\title{
Intimate Association of PRR- and NLR-Mediated Signaling in Plant Immunity
}

\author{
You Lu² and Kenichi Tsuda ${ }^{1+\dagger}$ \\ ${ }^{1}$ State Key Laboratory of Agricultural Microbiology, Interdisciplinary Sciences Research Institute, College of Plant Science and \\ Technology, Huazhong Agricultural University, Wuhan 430070, China \\ ${ }^{2}$ Department of Plant and Microbial Biology, Microbial and Plant Genomics Institute, University of Minnesota, St. Paul, MN \\ 55108, U.S.A. \\ Accepted 12 October 2020.
}

\begin{abstract}
Plants recognize the presence or invasion of microbes through cell surface-localized pattern recognition receptors (PRRs) and intracellular nucleotide-binding domain leucine-rich repeat receptors (NLRs). Although PRRs and NLRs are activated by ligands located in different subcellular compartments through distinct mechanisms, signals initiated from PRRs and NLRs converge into several common signaling pathways with different dynamics. Increasing evidence suggests that PRR- and NLR-mediated signaling extensively crosstalk and such interaction can greatly influence immune response outcomes. Sophisticated experimental setups enabled dissection of the signaling events downstream of PRRs and NLRs with fine temporal and spatial resolution; however, the molecular links underlying the observed interactions in PRR and NLR signaling remain to be elucidated. In this review, we summarize the latest knowledge about activation and signaling mediated by PRRs and NLRs, deconvolute the intimate association between PRR- and NLR-mediated signaling, and propose hypotheses to guide further research on key topics.
\end{abstract}

Keywords: elicitors, ETI, MAMPs, NLR, PAMPs, PRR, PTI

The plant innate immune system is required for fending off microbial pathogens (Zhou and Zhang 2020). Increasing evidence has also shown that it is also essential for assembly of healthy microbiota which can contribute to plant growth and health (Chen et al. 2020; Fitzpatrick et al. 2020). Presence and activities of certain microbes are recognized by plant immune receptors that activate orchestrated downstream signaling, thereby mounting appropriate immunity (Bigeard et al. 2015; Cui et al. 2015). The recognized molecules can be of microbial origin or host plant origin. For instance, peptides of bacterial flagellin (Felix et al. 1999), elongation

${ }^{\dagger}$ Corresponding author: K. Tsuda; tsuda@mail.hzau.edu.cn

Funding: This work was supported by the Fundamental Research Funds for the Central Universities (program number 2662020ZKPY009) to K. Tsuda, the Huazhong Agricultural University Scientific \& Technological SelfInnovation Foundation (to K. Tsuda), and Y. Lu was supported through the National Science Foundation grant IOS-1645460 to F. Katagiri and J. Glazebrook.

The author(s) declare no conflict of interest.

$($ (1) $\circledast \Theta$ Copyright $\odot 2021$ The Author(s). This is an open access article distributed under the CC BY-NC-ND 4.0 International license. factor Tu (EF-Tu) (Kunze et al. 2004), fungal chitin (Shibuya and Minami 2001), and pathogen effector proteins are recognized by plant immune receptors. Plants can detect their own molecules such as oligogalacturonides (OGs) released from plant cell walls (Ferrari et al. 2013), extracellular ATP (Tanaka et al. 2014), or plant elicitor peptides (Huffaker et al. 2006) as a danger signal.

Plant immune receptors can be broadly divided into two groups based on their subcellular localization and protein structure: cell surface-localized pattern recognition receptors (PRRs) and intracellular nucleotide-binding domain and leucine-rich repeat receptors (NLRs) (Dodds and Rathjen 2010). Whereas PRRs recognize their corresponding ligands present in the extracellular space, NLRs detect pathogen effector proteins within cells. This distinction coincides with the two branches of the plant immune system in the classical zigzag model (Jones and Dangl 2006). In this model, the first branch is activated by host recognition of pathogen- or microbe-associated molecular patterns (PAMPs or MAMPs, respectively), resulting in PAMP-triggered immunity (PTI) or MAMP-triggered immunity (also called patterntriggered immunity). PTI can be defeated by virulence effectors from pathogens, resulting in effector-triggered susceptibility (Jones and Dangl 2006). Some effectors are recognized, activating the second branch of the immune system called effectortriggered immunity (ETI). Historically, these recognized effectors were often named avirulence (Avr) proteins, because they make the pathogen nonvirulent. Some pathogens overcome ETI by losing the recognizable effectors, gaining new effectors, or changing subcellular localization (Asai et al. 2018). Some plants have evolved to recognize the new effector, reestablishing ETI. This allows plants to return to a resistant state. This zigzag model has been widely accepted in the research community because it is simple and captures the coevolutionary dynamics of the arms race between host and pathogen (Jones and Dangl 2006). The distinction between PTI and ETI has been a useful framework to explain the plant immune system. However, accumulating evidence shows that they share a number of signaling components and are intertwined. Indeed, the question "Does ETI potentiate and restore PTI or is there really a binary distinction between ETI and PTI?" was raised as one of the Top 10 unanswered questions in Molecular Plant-Microbe Interactions during the 2019 IS-MPMI conference (Harris et al. 2020). This reflects a need in the community to reenvision the framework of the plant immune system. There is another problem regarding the distinction of PTI and ETI when they are mechanistically explained. We discuss this issue in the section below. 


\section{DEFINING IMMUNITY MODES MECHANISTICALLY ACCORDING TO RECEPTOR TYPES RATHER THAN LIGAND TYPES}

Historically, PRRs and NLRs are considered as mediating PTI and ETI signaling, respectively. PRRs are associated with many cases of PTI and functions for recognition of MAMPs, apoplastic effectors, and damage-associated molecular patterns (DAMPs). NLRs are generally associated with ETI and function for recognition of effectors secreted into the host cytoplasm. However, the dichotomy between PTI and ETI has become blurred due to many recent discoveries of immune responses mediated by the combination of recognized molecules and corresponding plant receptors that cannot be unequivocally associated with traditional PTI or ETI. For example, the glycoside hydrolase 12 protein XEG1 secreted by the soybean root rot oomycete pathogen Phytophthora sojae promotes virulence through its xyloglucanase activity but is also recognized, triggering immune responses (Ma et al. 2015). This mode of immunity would be classified as ETI because XEG1 is an effector which triggers immunity. However, it was later revealed that recognition of XEG1 by the cell surface immune receptor RXEG1 in Nicotiana benthamiana closely resembles recognition of MAMPs and that the xyloglucanase activity of XEG1 is dispensable for its recognition; therefore, this mode of recognition was defined as PTI (Ma et al. 2015; Y. Wang et al. 2018b). Moreover, some microbial molecules are recognized by neither PRRs nor NLRs. For instance, transcription activator-like effectors (TALEs) produced by Xanthomonas spp. function by binding to specific DNA sequences to activate host genes, thereby promoting virulence (Bogdanove et al. 2010). In the resistant host, immune executer genes (not necessarily encoding NLRs) are transcriptionally activated by TALEs and, thus, function as resistance gene activation traps (Bogdanove et al. 2010; Zhang et al. 2015). Therefore, signaling processes associated with PTI or ETI need to be elaborated based on the recognition mechanism in a caseby-case fashion. Here, to better understand the signaling mechanisms, we deconvolute the signaling processes mediated by PRRs and NLRs because defining the modes of immunity by the types of host immune receptors provides a better mechanistic classification of the host immune response. Similar conceptual frameworks have been proposed in recent reviews (Kanyuka and Rudd 2019; van der Burgh and Joosten 2019). In this review, we first summarize the current knowledge of signaling mechanisms mediated by PRRs and NLRs. Then, we discuss the interaction between PRR and NLR signaling. Finally, we outline the unsolved questions regarding the intimate association of PRR and NLR signaling.

\section{ACTIVATION AND SIGNALING MECHANISMS OF PRRS}

The plant cell surface-localized immune receptors can be further classified into two major types: receptor like kinases (RLKs) that contain an ectodomain for ligand-binding, a singlepass transmembrane domain, and a cytoplasmic kinase domain; and receptor-like proteins (RLPs) that have domain structures similar to RLKs, except for a short cytoplasmic tail in lieu of a kinase domain (Couto and Zipfel 2016). For both RLKs and RLPs, the ligand-binding specificity is predominantly determined by different types of ectodomains, which include leucine-rich repeat (LRR) domains for proteinaceous ligands, LysM domains for glycans, lectin domains for carbohydrates, and epidermal growth factor-like repeat domains found in wallassociated kinase family receptors for OGs released from plant cell walls (Saijo et al. 2018).
RLKs and RLPs form dynamic heteromeric core receptors with coreceptors in a ligand-dependent manner. For instance, BRI1-ASSOCIATED RECEPTOR KINASE 1/SOMATIC EMBRYOGENESIS RECEPTOR KINASE 3 (BAK1/SERK3) and its close homolog BAK1-LIKE 1 (BKK1/SERK4) function as coreceptors for LRR-RLK-type PRRs such as FLAGELLIN SENSING 2 (FLS2) (Chinchilla et al. 2007) and EF-TU RECEPTOR (EFR) (Roux et al. 2011). Biochemical and structural analysis revealed that flg22, a bacterial flagellin epitope, induces formation of an FLS2-BAK1 heterocomplex within seconds through direct interaction with the LRR domains of both FLS2 and BAK1. The C-terminal segment of flg22 appears to act as a molecular glue of the FLS2-BAK1 complex (Sun et al. 2013). Formation of this core receptor for flg22 recognition results in transphosphorylation of both proteins that is crucial for mediating downstream signaling (Schulze et al. 2010; Sun et al. 2013). The LysM-RLK CHITIN ELICITOR RECEPTOR KINASE 1 (CERK1) is an essential coreceptor for recognizing fungal chitin and bacterial peptidoglycans (Miya et al. 2007; Wan et al. 2008; Willmann et al. 2011). In Arabidopsis, chitin treatment induces formation of a LYSIN MOTIF RECEPTOR KINASE 5 (LYK5)-CERK1 core receptor and phosphorylation of CERK1 kinase domain (Cao et al. 2014). LYK5 exhibits much higher affinity for binding to chitin than CERK1 (Cao et al. 2014), whereas CERK1 contributes to recognition of chitin through interaction between its LysMcontaining ectodomain and chitin residues (Liu et al. 2012). In rice, LysM-RLP CHITIN-ELICITOR BINDING PROTEIN $(\mathrm{CEBiP})$ is the major chitin receptor and chitin induces formation of a heterooligomeric core receptor consisting of CEBiP and CERK1 (Hayafune et al. 2014; Shimizu et al. 2010). For both BAK1 and CERK1 coreceptors, their kinase activity is indispensable for mediating downstream signaling (Petutschnig et al. 2010; Schwessinger et al. 2011).

The LRR-RLK protein SUPPRESSOR OF BAK1-INTERACTING RECEPTOR-LIKE KINASE (BIR)1-1/EVERSHED (SOBIR1/EVR) constitutively interacts with many LRR-RLPs (Liebrand et al. 2013), thereby forming a bimolecular equivalent unit of LRRRLKs (Gust and Felix 2014). For example, Arabidopsis RLP23, a receptor for the nlp20 epitope of necrosis and ethyleneinducing peptide 1-like proteins, physically associates with SOBIR1 in the absence of the ligand and recruits BAK1 upon recognition of nlp20 (Albert et al. 2015). A recent study suggested that immune signaling and cell death triggered by activation of tomato LRR-RLP Cf-4 and mediated by SOBIR1 is dependent on its transphosphorylation by BAK1 (van der Burgh et al. 2019), reminiscent of transphosphorylation between kinase domains of RLKs and BAK1. In these cases, LRR-RLP, SOBIR/EVR, and BAK1 are defined as core receptors.

Receptor-like cytoplasmic kinases (RLCKs) are direct substrates of heteromeric core receptors, connecting ligand recognition to downstream responses. Many RLCK VII family members have been reported to contribute to RLK-mediated signaling. Arabidopsis BOTRYTIS-INDUCED KINASE 1 (BIK1) and its close homolog PBS-LIKE 1 (PBL1) have been shown to play crucial roles in mediating downstream signaling upon flg22, elf18, chitin, and pep1 recognition in Arabidopsis (Couto and Zipfel 2016; Liu et al. 2013; Zhang et al. 2010). Upon recognition of flg22, BIK1 is phosphorylated by BAK1 and monoubiquitinated by E3 ubiquitin ligases RHA3A and RHA3B, resulting in its dissociation from the FLS2-BAK1 heteromeric core receptor (X. Ma et al. 2020; Zhang et al. 2010). Another Arabidopsis RLCK VII family member, PBL27, is phosphorylated by the chitin core receptor LYK5-CERK1 upon ligand binding and connects chitin recognition to downstream responses (Shinya et al. 2014). Similarly, in rice, RLCK VII family member RLCK185 is phosphorylated by CERK1 upon chitin treatment 
(Yamaguchi et al. 2013). Recently, the receptor for mediumchain 3-hydroxy fatty acids (mc-3-OH-FAs) in Arabidopsis LIPOOLIGOSACCHARIDE-SPECIFIC REDUCED ELICITATION (LORE) was shown to phosphorylate three closely related RLCK VII family members (PBL34, PBL35, and PBL36) upon elicitation, and PBL34, PBL35, and PBL36 redundantly mediate signaling downstream of LORE-mediated recognition of mc-3-OH-FAs (Luo et al. 2020).

RLCK XII family members BSK1 and BSK5 also contribute to PRR-mediated signaling events. BSK1 physically associates with FLS2 and positively regulates a subset of downstream signaling (Shi et al. 2013). BSK5 interacts with and can be transphosphorylated by Arabidopsis PRRs PEP1 RECEPTOR 1 (PEPR1) and EFR but not FLS2, and contributes to defense responses elicited by pep1, elf18, and flg22 (Majhi et al. 2019). It is possible that BSK5 is associated with the flg22 core receptor indirectly, such as through other RLCKs known to interact with FLS2.

\section{ACTIVATION MECHANISMS OF NLRS}

Plant NLRs can detect pathogen effectors secreted into the host cytoplasm either directly or indirectly through monitoring the homeostasis or modification of host proteins targeted by effectors. Most NLRs consist of a variable N-terminal domain, a central nucleotide-binding (NB) Apaf1-resistance-CED4 (ARC) domain, and a C-terminal LRR domain, although unusual integrated domains or truncated variants have been discovered in many plant genomes and these variants have been found to be active in plant immunity (Monteiro and Nishimura 2018). Depending on the composition of their N-terminal domains, NLRs can be further classified into three major types: coiled-coil (CC), Toll interleukin-1 receptor (TIR), or RPW8 $\left(\mathrm{CC}_{\mathrm{R}}\right)$. Sensor NLRs, regardless of functioning as "singleton NLR" or in pairs, are usually specialized in recognition of pathogen effectors, while helper NLRs are needed to execute signaling for some sensor NLRs (Adachi et al. 2019b). Thus far, three helper NLR families have been reported: the $\mathrm{CC}_{\mathrm{R}}$-type ACTIVATED DISEASE RESISTANCE 1 (ADRI) and N REQUIRED GENE 1 (NRG) families that coevolved with ENHANCED DISEASE SUSCEPTIBILITY1 (EDS1) family immune regulator proteins (Lapin et al. 2019), and a Solanaceae-specific NLR required for cell death (NRC) family (Wu et al. 2017). All characterized TIRtype NLRs are functionally dependent on ADR1 family or NRG family helper NLRs in Arabidopsis (Saile et al. 2020; Wu et al. 2019), while both helper NLR families quantitatively contribute to signaling activated by CC-type NLRs (Saile et al. 2020). The immediate downstream signaling mechanism following activation of NLRs remains largely unknown.

Recent advances in structure and biochemical activity of CC-type and TIR-type NLRs provided hints to bridge this knowledge gap. The structure of an NLR resistosome complex consisting of an Arabidopsis CC-type NLR ZAR1, a pseudokinase RKS1 belonging to RLCK XII family, and a decoy kinase PBL2 belonging to RLCK family VII has recently been resolved (Wang et al. 2019a,c). In the resting state, the ADPbound ZAR1 associates with RKS1 as monomers through the interface in the LRR domain of ZAR1. Upon uridylylation of PBL2 by the bacterial pathogen Xanthomonas campestris effector AvrAC, PBL2 ${ }^{\mathrm{UMP}}$ binds to RKS1 and induces conformational changes in the activation segment of RKS1 which, in turn, causes steric clash with the NB domain of ZAR1 and the release of ADP. The activated ZAR1-RKS1-PBL2 ${ }^{\mathrm{UMP}}$ assembles into a pentameric wheel-like structure called "resistosome" with the N-terminal $\alpha$ helix $(\alpha 1)$ of ZAR1 exposed, forming a funnel-shaped structure. Further mutational analysis revealed that both plasma membrane-association and the inner surface of the funnel-shaped structure are required for its function. Although the biochemical activity of the ZAR1RKS1-PBL2 ${ }^{\mathrm{UMP}}$ resistosome remains to be elucidated, the resistosome appears to also be formed in the plant cell $(\mathrm{Hu}$ et al. 2020). A 21-amino-acid "MADA motif" was identified to be conserved in the $\mathrm{N}$-terminal helical domains in nearly $20 \%$ of all CC-type NLRs from angiosperm plants, including Arabidopsis ZAR1 and an N. benthamiana helper NLR, NRC4 (Adachi et al. 2019a), suggesting that approximately $20 \%$ of CC-type NLRs may use a signaling mechanism similar to ZAR1.

The TIR-type NLR Roq1 in N. benthamiana recognizes the bacterial effectors XopQ1 and HopQ1 from X. euvesicatoria and Pseudomonas syringae, respectively, resulting in hypersensitive response (HR) and disease resistance (Schultink et al. 2017). The structure of an active XopQ-bound Roq1 resistosome purified from leaf tissues of $N$. benthamiana has been recently resolved (Martin et al. 2020). Unlike ZAR1 that requires additional components to recognize pathogen effectors, Roq1 directly recognizes XopQ through multiple contact interfaces present on the LRR domain and the post-LRR domain of Roq1. In addition, XopQ-bound Roq1 assembles into a tetrameric resistosome, in contrast to the pentameric organization found in the ZAR1 resistosome. Multiple TIR-type NLRs or TIR-only proteins have been demonstrated to be capable of cleaving $\mathrm{NAD}^{+}$into nicotinamide, adenosine diphosphate ribose (ADPR), and a variant of cyclic ADPR (v-cADPR) (Horsefield et al. 2019; Wan et al. 2019). This enzymatic activity is dependent on both a conserved putative catalytic glutamic acid residue located in the TIR domain and dimerization interfaces, and is highly correlated with the ability to cause cell death. In the Roq1 resistosome, tetramerization driven by reconfiguration of NB-ARC domain conformation brings the TIR domain of the four protomers into close proximity, leading to repositioning of the BB-loop in two of the four TIR domain units and, consequently, exposing the NADase active site (Martin et al. 2020). Cell death triggered by plant TIRs was dependent on EDS1, a central signaling hub in the plant immune system (Wan et al. 2019), consistent with the established observation that all of the characterized plant TIR-type NLRs require EDS1 to function (Lapin et al. 2020). v-cADPR accumulation triggered by a plant TIR does not need EDS1 (Wan et al. 2019). These results suggest that depletion of $\mathrm{NAD}^{+}$or degradation products of $\mathrm{NAD}^{+}$signals through EDS1 to trigger cell death. In contrast, an autoactive fragment derived from the mammalian TIR-domain-containing protein SARM1 caused cell death in $N$. benthamiana independently of EDS1 (Wan et al. 2019), suggesting that plant TIRs function through a different mechanism from that for mammalian SARM1. Although $\mathrm{NAD}^{+}$cleavage activity is essential for TIR-type NLR function, a recent study using chimeric NLRs containing plant TIR domains fused to mammalian NLRC4 at the N terminus, enabling NLRC4-imposed induced proximity of TIR domains, suggested that ADPR and V-cADPR production alone is not sufficient to induce cell death in plants (Duxbury et al. 2020). How ADPR and v-cADPR are perceived in plants, how they are connected to downstream signaling events through EDS1 and helper NLRs, and what other activities TIR-type NLRs possess in addition to cleaving $\mathrm{NAD}^{+}$are still under investigation.

\section{COMMON IMMUNE RESPONSES IN PRR AND NLR SIGNALING}

PRR- and NLR-mediated signaling are initiated at separate subcellular locations by distinct receptor complexes, and the genetic requirements differ at their early steps. Increasing evidence suggests that common signaling components are 
differentially used by both signaling systems (Mine et al. 2018; Tsuda and Katagiri 2010; Tsuda et al. 2009). Multiple downstream responses can be activated during both PRR-mediated and NLR-mediated signaling, including the influx of $\mathrm{Ca}^{2+}$, reactive oxygen species (ROS) burst, activation of mitogenactivated protein kinase (MAPK) cascades, defense gene induction, and biosynthesis of defense phytohormones (Fig. 1). These facts strongly suggest that PRR- and NLR-mediated signaling converge at a component upstream of those immune responses. Below, we discuss how and where signaling mediated by PRR and NLR receptors might converge to activate similar immune responses.

\section{Calcium signaling.}

Calcium serves as a common second messenger for signaling in eukaryotic cells. Plants are capable of generating specific patterns of $\mathrm{Ca}^{2+}$ signals (encoders) to respond to various developmental processes or stress conditions (Tian et al. 2020). In rice, CYCLIC NUCLEOTIDE-GATED CHANNEL 9 (OsCNGC9) has been shown to be a $\mathrm{Ca}^{2+}$-permeable inward channel, and is responsible for chitin- and flg22-induced $\mathrm{Ca}^{2+}$ influx (Wang et al. 2019b). The channel activity of OsCNGC9 can be activated by OsRLCK185 in a heterologous system but the mechanism of how this channel activity is regulated in rice upon recognition of MAMPs has not been elucidated. In Arabidopsis, flg22-induced $\mathrm{Ca}^{2+}$ influx can be detected within minutes of flg 22 recognition, and is mediated by a heteromeric channel composed of CNGC2 and CNGC4 (Tian et al. 2019).
The CNGC2-CNGC4 channel is activated upon phosphorylation of the C-terminal cytosolic domain of CNGC4 by BIK1. The Arabidopsis cngc2 and cngc4 mutants have been previously identified as defense, no death ( $d n d) 1$ and $d n d 2$, respectively, that display disease resistance and inhibition of HR cell death triggered by Avr proteins, in a genetic screen for defects in the CC-type NLR RPS2-mediated HR (Clough et al. 2000; Jurkowski et al. 2004), linking their ability for $\mathrm{Ca}^{2+}$ influx to NLR-mediated signaling. Indeed, blocking calcium channels can significantly delay onset of $\mathrm{HR}$ cell death (Xu and Heath 1998). However, how the $\mathrm{Ca}^{2+}$ influx is achieved and regulated during NLR-mediated signaling remains unknown. The revelation of the structure of ZAR1 resistosome provides hints that the funnel-shaped structure may serve as a pore or a channel; for example, as a calcium channel which could mediate calcium influx to kickstart NLR signaling. Indeed, sustained calcium influx has been reported for resistance signaling mediated by another CC-type NLR protein, RPM1 (Grant et al. 2000), although whether activated RPM1 can form a funnelshaped structure similar to ZAR1 is yet to be shown. Because $\mathrm{HR}$ cell death is compromised in the $d n d$ mutants, it is possible that CC-type NLRs coordinate with CNGC2/4 for $\mathrm{Ca}^{2+}$ influx to initiate $\mathrm{HR}$. The cleavage products of $\mathrm{NAD}^{+}$produced by plant TIR-type NLRs ADPR and v-cADPR share structural similarity to cADPR, which is known to be a potent $\mathrm{Ca}^{2+}$. releasing secondary messenger molecule in eukaryotic cells, including plants (Guse 2004; Wu et al. 1997). It would be interesting to investigate whether the $\mathrm{NAD}^{+}$degradation

\section{PRR-mediated signaling}

\section{NLR-mediated signaling}

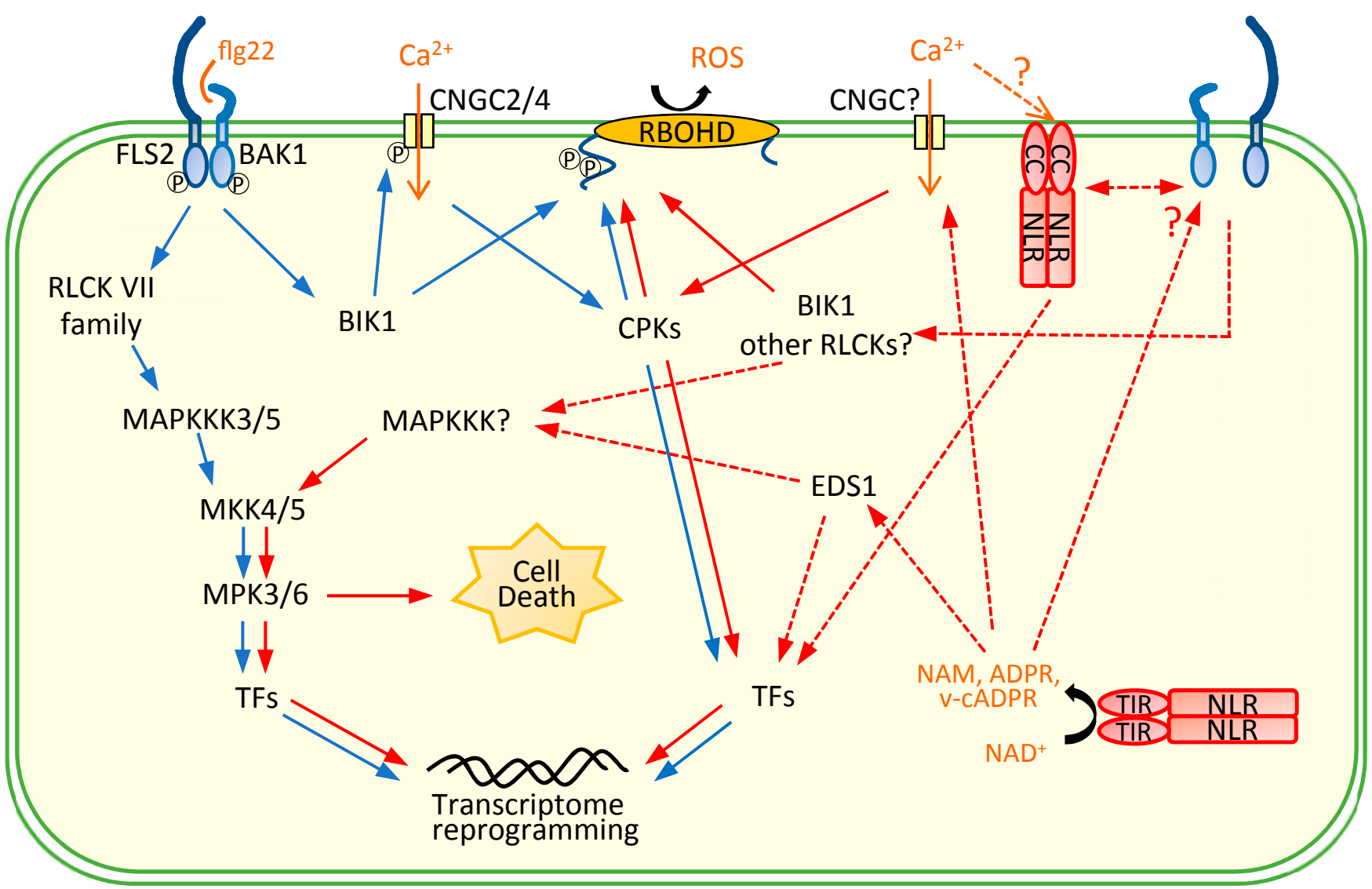

Fig. 1. Convergence of pattern recognition receptor (PRR) and nucleotide-binding domain leucine-rich repeat receptor (NLR) signaling. PRR- and NLRmediated signaling are shown in blue and red, respectively. Solid arrows indicate signaling events with known mechanisms. Dashed arrows indicate that the molecular basis for the signaling process is not understood. Question marks denote that the connection has not been experimentally revealed. 
products in plants also induce calcium influx and whether such a property is EDS1 and helper NLR dependent. Taken together, these observations suggest that $\mathrm{Ca}^{2+}$ release is a convergence point in both PRR- and NLR-mediated signaling.

The $\mathrm{Ca}^{2+}$-influx signatures can then be decoded by different $\mathrm{Ca}^{2+}$ sensor proteins. The $\mathrm{Ca}^{2+}$-dependent protein kinases (CPKs) play prominent roles in relaying signals downstream of both activated PRRs and NLRs. In Arabidopsis, CPK28 negatively regulates PRR-mediated signaling by phosphorylating a pair of plant U-box E3 ubiquitin ligases (PUB25 and PUB26) which, in turn, promotes BIK1 degradation (J. Wang et al. 2018). CPK4, CPK5, CPK6, and CPK11 positively regulate MAMP-induced ROS burst by phosphorylating RBOHD (discussed below) (Boudsocq et al. 2010; Dubiella et al. 2013). During NLR signaling mediated by RPM1 and RPS2, CPK1, CPK2, CPK4, and CPK11 have been shown to phosphorylate RBOHD to promote ROS production, whereas CPK4, CPK5, CPK6, and CPK11 phosphorylate a suite of WRKY transcription factors to regulate gene expression (Gao et al. 2013).

\section{ROS signaling.}

ROS play a central role in plant immunity as signaling molecules as well as direct weapons against pathogens (Ishiga and Ichinose 2016; Qi et al. 2017; Torres 2010). A burst of extracellular ROS is another hallmark of early responses following PRR activation. In Arabidopsis, the plasma membrane-localized NADPH oxidase RBOHD is physically associated with PRR complexes (Kadota et al. 2014; Li et al. 2014). Upon elicitation of PRR complexes, the activity of RBOHD is positively regulated through phosphorylation of the $\mathrm{N}$ terminus at Ser39, Ser339, and Ser343 by BIK1; at Ser133, Ser148, and Ser163 by calcium-dependent CPK4, CPK5, CPK6, and CPK11; and at Ser347 by both BIK1 and CPKs (Dubiella et al. 2013; Kadota et al. 2014). Ser339 and Ser347 of RBOHD can also be phosphorylated in vitro by a conserved Arabidopsis MAP4 kinase SIK1, and SIK1 contributes to phosphorylation of Ser347 in vivo upon flg22 treatment (Zhang et al. 2018). Phosphorylation of these residues is required for RBOHD to reach full ROS production triggered by MAMPs. The $\mathrm{C}$ terminus of RBOHD, on the other hand, consists of phospho-sites with either positive or negative regulatory roles. Arabidopsis CYSTEINE-RICH RLK2 targets Ser703 and Ser862 of RBOHD for enhancing or repressing the ROS production when cotransfected in HEK293T cells (Kimura et al. 2020). The RLCK PBL13-mediated phosphorylation of the RBOHD C terminus at Ser862 and Thr912 facilitates ubiquitination by PBL13 INTERACTING RING DOMAIN E3 LIGASE and reduces ROS production elicited by flg22 treatment (Lee et al. 2020). Therefore, the activity and protein abundance of RBOHD is tightly modulated by various groups of kinases at both $\mathrm{N}$ - and $\mathrm{C}$-terminal regions to fine tune the ROS production upon MAMP perception.

Recently, a pair of studies using inducible systems to investigate NLR-mediated signaling independently found that RBOHD-dependent ROS production also occurs an approximately 90 min after activation of the Arabidopsis CC-type NLR RPS2 in the absence of the pathogens (Ngou et al. 2020a; Yuan et al. 2020). Interestingly, activation of the CC-type NLR RPS2 also induces strong phosphorylation of Ser163, Ser343, and Ser347 of RBOHD, overlapping with the phosphorylation sites for activation during PRR-mediated signaling (Kadota et al. 2019; Yuan et al. 2020). CPKs commonly involved in PRR and NLR signaling as well as BIK1 are candidate upstream kinases for RBOHD phosphorylation in NLR signaling because the sites in RBOHD phosphorylated during NLR activation are phosphorylated by CPKs and BIK1 during PRR activation. However, ROS production induced by bacterially delivered AvrRpt2 (Yuan et al. 2020) or AvrRpm1 (Kadota et al. 2019) was virtually unaffected in mutants, including bikl and $c p k 5 / 6 / 11$, possibly due to functional redundancy among homologs of BIK1 and CPKs. Which kinases mediate phosphorylation of RBOHD and how these kinases are activated downstream of NLR activation remains to be elucidated. It is worth noting that activation of TIR-type NLRs RRS1 or RPS4 by induced expression of AvrRps4 cannot trigger ROS production (Ngou et al. 2020a), possibly due to divergence in downstream signaling pathways between CC-type and TIRtype NLR.

Calcium signaling and extracellular ROS can mutually activate each other (Gilroy et al. 2016), potentially amplifying and spreading immune signals to neighboring cells and systemic tissues. The RLK HYDROGEN-PEROXIDE-INDUCED $\mathrm{CA}^{2+}$ INCREASES 1 (HPCA1) was recently identified as an extracellular $\mathrm{H}_{2} \mathrm{O}_{2}$ sensor in plants. $\mathrm{H}_{2} \mathrm{O}_{2}$-induced $\mathrm{Ca}^{2+}$ influx was severely compromised in hpcal mutant plants (F. Wu et al. 2020). Although flg22- or elf26-induced initial $\mathrm{Ca}^{2+}$ influx was not affected in hpcal mutant plants, flg22 treatment increased the level of phosphorylation in HPCA1, implying its involvement in FLS2-mediated signaling. It would be interesting to investigate whether and how HPCA1 and its homologs are involved in shaping the $\mathrm{Ca}^{2+}$ encoding during PRR-and NLRmediated signaling.

\section{MAPK signaling.}

MAPK cascades connect PRR complexes to downstream responses in the cytoplasm and nucleus through phosphorylating their substrate proteins. In Arabidopsis, two parallel MAPK cascades are involved in immune signaling: the MAPKKK3/5-MKK4/5-MPK3/6 cascade and the MEKK1MKK1/2-MPK4 cascade. The long-sought molecular link between PRR complexes and MAPK cascades has recently been discovered. MAPKKK3 and MAPKKK 5 are phosphorylated in response to flg22, elf18, chitin and Pep2, and phosphorylation at Ser599 on MAPKKK5 requires RLCK VII family members (Bi et al. 2018). Phosphorylation at Ser599 is required for MAPKKK5 to activate MPK3 and MPK6 via MKK4 and MPK5 and for mediating disease resistance conferred by recognition of MAMPs. Similarly, MEKK1 is phosphorylated at Ser603 by RLCK VII family members and this phosphorylation is required for activating MPK4 via MKK1 and MKK2 and for suppressing SUMM2-mediated autoimmunity (Bi et al. 2018). Although MAPK activation by MAMP treatment or virulent bacterial pathogens is fast and transient, recognition of $P$. syringae effector AvrRpt2, delivered by bacteria or expressed from a transgene by Arabidopsis CC-type NLR protein RPS2, triggers sustained MAPK activation (Tsuda et al. 2013). Sustained MAPK activation can regulate the immune phytohormone salicylic acid (SA)-responsive genes in an SA-independent manner (Tsuda et al. 2013) and is essential for ROS accumulation in chloroplasts and inhibition of photosynthesis $(\mathrm{Su}$ et al. 2018). The Arabidopsis secondary metabolite L-pipecolic acid (Pip) and its derivative are crucial for mediating systemic acquired resistance (SAR), which is systemic, broadspectrum resistance induced upon localized pathogen exposure (Hartmann and Zeier 2019). Pip can activate MAPKs in a BAK1- and BKK1-dependent manner, and genes involved in the biosynthetic pathway of Pip are required for sustained MAPK activation mediated by RPS2 (Y. Wang et al. 2018a). It is not yet known which MAPKKK is activated during NLRmediated signaling or how this occurs. It is worth noting that, unlike AvrRpt2, recognition of AvrRps4 by a pair of TIR-type NLR proteins (RPS4 and RRS1) triggers sustained MAPK activation only when AvrRps4 is delivered by bacteria or is expressed with concomitant treatment with flg22, not when it is expressed in transgenic plants (Ngou et al. 2020b), suggesting 
that the mechanisms linking NLRs to activation of MAPK cascades may be different between CC-type and TIR-type NLRs. Despite divergence in signaling pathways linking NLRs to MAPK cascades, a functional MAPK cascade is required for mediating cell death triggered by activation of both CC- and TIR-type NLRs (Ngou et al. 2020a; Su et al. 2018). Taken together, MAPK cascades serve as a convergent point downstream of PRRs and both types of NLRs.

\section{CROSSTALK BETWEEN PRR- AND NLR-MEDIATED SIGNALING}

Traditionally, NLR-mediated signaling was studied using effectors delivered by pathogens or engineered bacterial strains. In such experiments, both MAMPs and effectors can be recognized by the plant, leading to activation of both PRR- and NLR-mediated signaling. The interaction between PRR- and NLR-mediated signaling was mostly ignored because there was no way to specifically block PRR signaling in these experimental designs. As a result, PRR- and NLR-mediated signaling were interpreted as independent events, even though it was recognized that they extensively share signaling machinery. However, results from several recent published studies clearly argued for the necessity of examining the interaction between PRR- and NLR-mediated signaling (Hatsugai et al. 2017; Ngou et al. 2020a; Yuan et al. 2020). All three studies utilized an inducible system for triggering NLR-mediated signaling in the absence of MAMPs, enabling dissection of the signaling events between the two modes of immunity.

\section{Antagonism between PRR and NLR signaling.}

Activation of PRRs incurs inhibitory effects on subsequent NLR-mediated signaling through a network-buffered signaling mechanism named the ETI-mediating and PTI-inhibited sector (EMPIS) (Hatsugai et al. 2017). The molecular identity of EMPIS has not been uncovered. Comparison of the transcriptomes between plants treated by flg22-only, AvrRpt2-only, and flg $22+$ AvrRpt 2 revealed that many kinase-encoding and $R L P$ genes are among the AvrRpt2-responding genes inhibited by PRR-mediated signaling, suggesting that these genes are part of NLR-mediated signaling and candidates for mediating EMPIS function. It is conceivable that plants have evolved mechanisms to assess the effectiveness of PRR signaling, and effective PRR signaling, which suggests no strong interference by pathogen effectors, subsequently feeds into decision-making programs for switching off more costly NLR-mediated response. One example corroborating this idea comes from the observation that deficiency in MEKK1-MKK1/2-MPK4 cascade activity following MAMP perception, caused by genetic perturbation or by $P$. syringae effector HopAI1, triggers autoimmunity mediated by the NLR protein SUMM2 together with MEKK2 and CRCK3 (Kong et al. 2012; Zhang et al. 2012, 2017). A pair of Catharanthus roseus RLK1-like (CrRLK1L) family malectin-like receptor kinases LETHALITY SUPPRESSOR OF MEKK1 1 (LET1) and LET2 form a trimeric protein complex with LORELEI-LIKE GLYCOSYLPHOSPHATIDYLINOSITOLANCHORED PROTEIN 1 (LLG1), and act upstream of SUMM2 in modulating its activity (Huang et al. 2020; Liu et al. 2020). Such mechanisms might allow plants to carefully suppress unnecessary immunity because immune responses are costly.

\section{Requirement of PRRs for full activation of NLR signaling.}

Two recent studies demonstrated that components associated with PRR signaling are required to achieve the full extent of NLR-mediated signaling in terms of macroscopic cell death and pathogen growth suppression (Ngou et al. 2020a; Yuan et al. 2020). Both studies identified a distinct RBOHDdependent ROS burst following induced expression of $A v r$ genes in plants. This ROS burst was much stronger and more sustained when the plants were elicited with a combination of flg22 and Avr proteins than the additive effect of single
A Cell-autonomous model

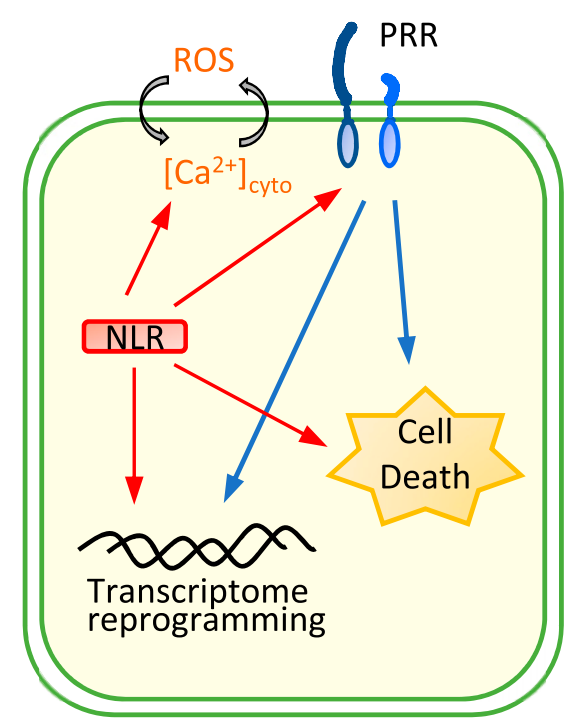

B

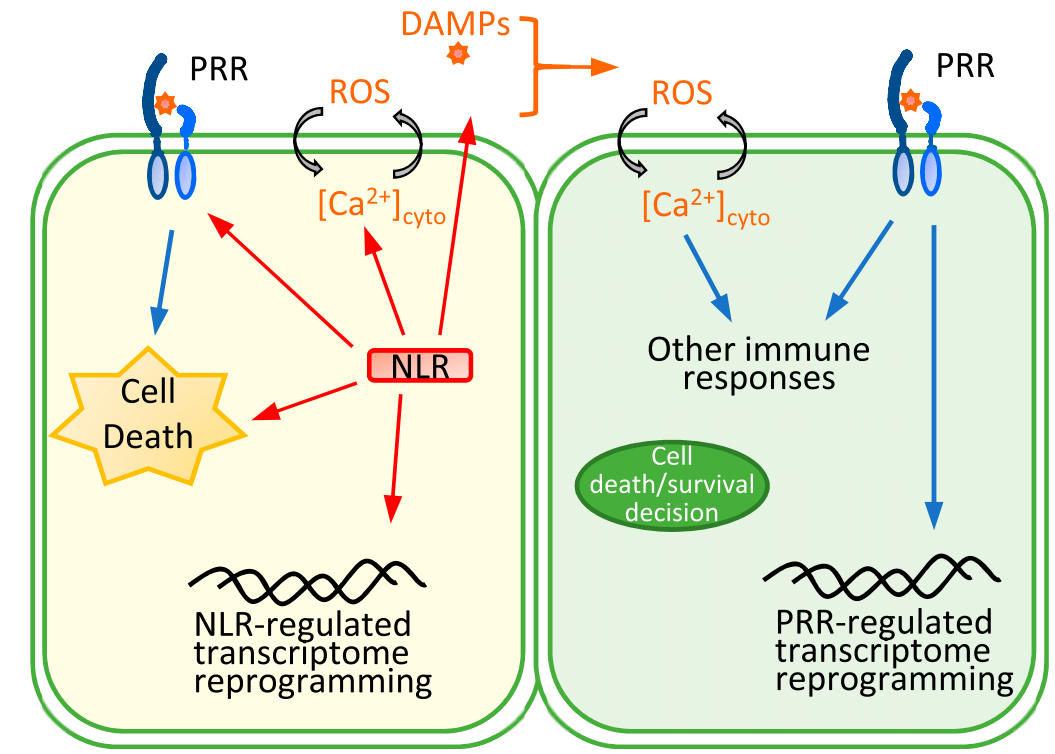

Fig. 2. Cell-autonomous and cell-nonautonomous models for the role of pattern recognition receptor (PRR) signaling components during nucleotide-binding domain leucine-rich repeat receptor (NLR) activation. A, In the cell-autonomous model, NLR and PRR signaling converge in the same cell in which NLR is activated and trigger immune responses. ROS = reactive oxygen species. $\mathbf{B}$, In the cell-nonautonomous model, NLR activation leads to production and release of damage-associated molecular patterns (DAMPs), which are recognized in neighbor cells where PRR signaling is activated. The signaling initiated from activation of NLR is shown as red arrows. Signaling events downstream of PRRs are shown as blue arrows. 
treatments, suggesting the presence of a synergistic interaction between signals initiated by PRRs and NLRs. Yuan et al. (2020) further demonstrated that induced expression of AvrRpt2, which activates RPS2, caused phosphorylation of Ser343 and Ser347 in RBOHD in a BAK1- and BKK1-dependent manner, and RPS2-mediated resistance to avirulent strain $P$. syringae DC3000 carrying AvrRpt2 was compromised in rbohd mutant plants, highlighting the importance of RBOHD-dependent extracellular ROS during both PRR- and NLR-mediated signaling. Previous research has demonstrated the vital roles of chloroplast-generated ROS in promoting HR cell death (Liu et al. 2007). Further investigation will help dissect their contributions to NLR-mediated signaling and whether chloroplastgenerated ROS also require functional PRRs.

Mutations in BAK1 and BKK1 compromise disease resistance conferred by activation of RPS2, RPS5, or RPS4 (Ngou et al. 2020a; Yuan et al. 2020), although the molecular link connecting NLR activation to BAK1 or BKK1 remains to be elucidated. CCtype NLR RPS2 has been reported to reside in the same protein complex with FLS2 (Qi et al. 2011). Thus, it is plausible that activation of a PRR and associated coreceptor may directly prime an NLR or its partner that coexists in the same complex, possibly through posttranslational modifications, and vice versa. Alternatively, it is possible that the heterocomplex consisting of PRR, coreceptor BAK1 or BKK1, and NLR may mediate at least part of the CC-type NLR activity such as HR cell death. Unlike CC-type NLRs that can mediate HR in the absence of pathogen or MAMP treatment, the TIR-type NLR RRS1/RPS4 or RPP4 is not sufficient to activate effector-triggered macroscopic cell death when the effector is transgenically expressed in Arabidopsis (Ngou et al. 2020b), suggesting a difference in dependency on PRR-mediated signaling for cell death induction. For both CC-type and TIR-type NLRs, transcriptome reprogramming and macroscopic cell death seems to be uncoupled because, in the PRR-signaling mutants, macroscopic cell death was compromised but transcriptome reprogramming remained intact (Ngou et al. 2020a; Yuan et al. 2020). However, it remains to be investigated whether cell death still occurs in a much more localized fashion in the PRR-signaling mutants.

BAK1 or BKK1 is required for mediating immune signaling, including HR cell death, initiated by many RLP-type PRRs. For example, the tomato orthologs of BAK1, SlSERK3a and -b, are required for mediating cell death triggered by $\mathrm{Cf}-4$ upon recognition of Cladosporium fulvum apoplastic effector Avr4 in tomato (Postma et al. 2016). BAK1 and BKK1 are known to be involved in cell death control in a protein-abundance-dependent manner. The double mutant bakl-4 bkkl-1 displayed constitutive defense responses (dwarfism and spontaneous cell death) (He et al. 2007). This phenotype can be partially restored to wild type by transgenically expressing $N a h G$ (He et al. 2007) or mutations in CNGC19 or -20 (Yu et al. 2019). On the other hand, overexpressing BAK1 also leads to autoimmune symptoms in a SOBIR1dependent manner (Domínguez-Ferreras et al. 2015). The mechanism of how cell death signaling is triggered by perturbation in homeostasis of BAK1 or BKK1 is not fully understood. Misregulation of $\mathrm{Ca}^{2+}$ influx due to derepression of CNGC19 and CNGC20 in the bakl-4 bkkl-1 mutant is one likely cause of cell death (Yu et al. 2019). Another plausible explanation for the spontaneous cell death phenotype in bakl-4 bkkl-1 mutant plants is that the abundance of BAK1 and BKK1 is monitored by an NLR; hence, depleting BAK1 and BKK1 would activate such an NLR. Although no NLR has been revealed yet to play such a role, identification of one suppressor gene of bakl bkkl, SBB1, which encodes a NUP85-like protein, along with several other nucleoporin components from the same complex, shed light on the involvement of nucleocytoplasmic trafficking control in BAK1/BKK1-regulated cell death signaling processes (Du et al.
2016). Changes in the nuclear pore permeability controlled by nucleoporins is a known mechanism during both CC- and TIRtype NLR-mediated signaling ( $\mathrm{Gu}$ et al. 2016). Finally, it has recently been shown that cell death triggered by loss of BAK1 and BKK1, genetically or cleaved by $P$. syringae effector HopB1, depends on ADR1 family helper NLRs, suggesting that BAK1 and its homologs are likely guarded by one or more NLRs (Y. Wu et al. 2020). Reliance on nuclear pore permeability control, Ca2+ influx, SA levels, and execution by helper NLRs implicates the similarity between cell death controlled by BAK1/BKK1 and mediated by NLRs. In wild-type plants, execution of cell death signaling through changes in homeostasis of BAK1/BKK1 may be achieved by transient depletion of BAK1/BKK1 through accelerated endocytosis (Russinova et al. 2004).

\section{POTENTIATION OF PRR SIGNALING BY NLR SIGNALING}

Activation of NLRs resulted in augmented expression levels of genes known to be responsive to MAMPs, including components of the core receptor modules and downstream signaling components such as RBOHD and MAPKs, hence potentiating the responses commonly associated with PRRmediated signaling (Adachi et al. 2015; Yuan et al. 2020; Ngou et al. 2020a). Such augmented expression of PRRsignaling components genes is likely mediated by the stressrelated phytohormones. The phytohormone signaling network enables rapid induction of PRR-signaling component genes upon activation of RPS2 (Mine et al. 2018), within an early time window that is crucial for the outcomes of host-pathogen interactions (Nobori et al. 2018). Similarly, potentiation of PRR signaling through augmented protein abundance of receptors has previously been reported in the gain-of-function acd6-1 mutant that accumulates high levels of SA and in plants treated with the SA agonist benzothiadiazole (Tateda et al. 2014).

The activities of the core receptors can be modified through interaction with other RLKs or RLPs. For example, BIR2 constitutively associates with the kinase domain of BAK1 and dissociates from the complex upon ligand recognition, thereby allowing core receptor module formation (Halter et al. 2014). FLS2-INTERACTING RECEPTOR (FIR) associates with FLS2 and positively regulates responses triggered by flg22 through facilitating flg22-induced FLS2-BAK1 complex formation (Smakowska-Luzan et al. 2018). The CrRLK1L family receptor kinase FERONIA, together with LLG1 and cell-wallassociated LRR-EXTENSINs, positively regulate formation of the FLS2-BAK1 heterocomplex upon flg22 recognition by controlling lateral mobility of FLS2 and its nanodomain organization on the plasma membrane (Gronnier et al. 2020; Shen et al. 2017; Stegmann et al. 2017), while mediating RAPID ALKALINIZATION FACTOR peptide-triggered inhibition of plant immunity in a ligand-dependent manner (Stegmann et al. 2017; Xiao et al. 2019). These characterized interactions between PRRs and additional RLKs manifest the complexity of organization of PRRs on plasma membranes and tight regulation on their activity.

Revelation of an LRR-based cell-surface interaction network shed light on understanding the regulatory principles governing the activities of LRR-RLKs as a network (Smakowska-Luzan et al. 2018). It would be interesting to test whether the topology of the RLK and RLP network changes upon immune elicitation, which would likely result in release of negative regulations normally present at the resting state or potentiating PRRs through uncharacterized interactions. A recent study on the mechanisms of crosstalk between core receptors for recognition 
of bacterial or fungal MAMPs identified BAK1-mediated priming of CERK1-mediated fungal resistance by phosphorylation in the juxtamembrane region of CERK1 (Gong et al. 2019). Altered interaction between some RLKs or RLPs upon reconfiguration of network topology may even permit ligandindependent activation of certain PRRs. Ligand-independent activation has been reported for a number of mammalian cellsurface-localized receptors. For instance, c-Met, a receptor tyrosine kinase that regulates cell proliferation, motility, and migration, can be activated by its canonical ligands, hepatocyte growth factor or scatter factor, and can also be activated ligand independently by the fibronectin receptor, $\alpha 5 \beta 1$ integrin, initiating alternative downstream signaling pathways (Mitra et al. 2011). The canonical Notch signaling is initiated by binding of the cell surface receptor Notch to its Notch ligands expressed on the surface of adjacent cells, resulting in the release of the Notch intracellular domain (NICD) from the transmembrane fragment of Notch which, in turn, is translocated to the nucleus and regulates crucial developmental steps in many cell types (Andersson et al. 2011). It has been shown that T-cell-specific activation of Notch is achieved through T-cell receptor stimulation without the Notch ligand in a process involving endocytosis of Notch and endosomal acidification, which eventually leads to release of NICD for downstream signaling (Steinbuck et al. 2018). In plants, ligand-independent activation of PRR signaling has not been reported but induced overexpression of coreceptor BAK1 alone can cause constitutive activation of defense responses, sustained MAPK activation, and cell death in the absence of pathogen or MAMP treatments (Domínguez-Ferreras et al. 2015). It would be interesting to test whether perturbation of homeostasis of BAK1and BKK1 may occur in a highly controlled and localized fashion during NLR-mediated signaling, and whether endocytosis is necessary for activation in a ligandindependent manner.

Virulent pathogens often secrete numerous effectors to suppress immune signaling initiated from PRRs, leading to disease susceptibility (Boller and He 2009). However, immune signaling mediated by NLRs is believed to overcome immune suppression by pathogen effectors and usually results in disease resistance (Mine et al. 2017). Although the hypothesis that NLRmediated signaling processes converge into PRR-mediated signaling for execution sounds appealing, it is perplexing to comprehend how the signaling pathways hijacked by other pathogen effectors can be reverted to functional status during NLR activation. Perhaps increased protein abundance of the components of RLK- or RLP-mediated signaling by activated NLR-mediated signaling can compensate for the suppressed functions incurred by pathogen effectors. For example, overexpression of a rice MAPKKK, OsMAPKKKe, resulted in enhanced OsCERK1-mediated signaling and resistance to blast fungus (Wang et al. 2017). It is also possible that there are undiscovered mechanisms that protect some targeted host proteins during NLR-mediated signaling. For instance, HopM1mediated degradation of AtMIN7, a crucial regulator of vesicle trafficking in plant immunity, can be blocked following AvrRpt2-, AvrPphB-, or HopA1-triggered NLR activation (Nomura et al. 2011). In addition, during AvrRpt2-triggered activation of the NLR RPS2, the bacterial effector HopAI1 is S-nitrosylated, which results in inability to inhibit MAPKs (Ling et al. 2017), pointing to a mechanism to overcome the function of pathogen effectors during NLR activation. Another possible explanation is that NLR could activate PRR-mediated signaling in neighboring cells that do not receive pathogen effectors. It would be interesting to test the latter hypothesis with techniques enabling single-cell level detection while maintaining the relative spatial information.

\section{CHALLENGES AHEAD}

The past three decades have witnessed marvelous advancement in our understanding of the plant innate immune system at the molecular level, including cloning of PRR and NLR genes, identification of corresponding ligands, revelation of structures of receptor-ligand complexes, and elucidation of activation mechanisms and downstream components for signaling. Many of these discoveries continuously reshape our knowledge and framework of plant innate immunity. In this review, we proposed a framework defined by the immune receptor types to precisely describe PRR- and NLR-mediated signaling, as well as their crosstalk. Although this framework provides a systemic view of how the plant innate immune system functions, there are several omissions due to a current lack of understanding in several areas highlighted below.

The mechanisms of plant immune signaling in response to a limited number of pathogens have been extensively characterized but much less is known about how the signaling machinery is utilized when plants interact with commensal microbes. It has been increasingly evident that PRR-mediated signaling is crucial for maintaining a healthy microbiome assembly (Chen et al. 2020). Indeed, transcriptional responses induced by rootassociated commensal bacteria closely resembled that of flg22 derived from pathogens (Stringlis et al. 2018). In addition, commensal bacteria can modulate the status of plant immunity. Colonization of commensal bacteria in Arabidopsis roots is required for its resistance against root-derived fungi and oomycetes (Durán et al. 2018). On the other hand, certain species of commensal bacteria can also suppress flg22mediated root growth inhibition (K.-W. Ma et al. 2020). How the commensals actively suppress plant immune responses mediated by PRRs and whether plant NLRs play a role in the interaction to achieve a balanced level of immunity remains to be elucidated.

Another obstacle for understanding how NLR-mediated signaling converges with PRR-mediated signaling is lack of knowledge about how signaling cascades activated by CC-type and TIR-type NLRs pass through NONRACE-SPECIFIC DISEASE RESISTANCE1 (NDR1) and EDS1, respectively. NDR1 localizes at the plasma membrane and shares structural similarity to integrin-like proteins (Knepper et al. 2011) and is required for many but not all CC-type NLRs (Day et al. 2006). NDR1 associates with RPM1 INTERACTING PROTEIN4 and mediates immune signaling initiated by multiple CC-type NLRs (Aarts et al. 1998; Day et al. 2006). On the other hand, EDS1 encodes for a nucleocytoplasmic protein containing an $\mathrm{N}$-terminal lipase-like domain and a C-terminal EP domain and is essential for the full activity of all tested TIR-type NLRs (Lapin et al. 2020). EDS1 forms heterodimers with either PHYTOALEXIN DEFICIENT 4 (PAD4) or SENESCENCEASSOCIATED GENE 101 to mediate distinct branches of downstream outputs. Although it has been shown that EDS1 and PAD4 interfere with transcription factor MYC2, which otherwise inhibits SA-mediated immunity (Cui et al. 2018), the biochemical function of NDR1 and EDS1 remains elusive, hindering precise positioning of the two signaling hubs in the context of crosstalk between PRR- and NLR-mediated signaling.

It is worth noting that the majority of current studies measured immune signaling outputs using whole tissues and, therefore, the obtained results were averaged across the entire tissue, obscuring the heterogenicity of the responses among cells. It is evident that, paradoxically, simultaneous activation of SA and jasmonic acid (JA) signaling in the same leaf infected by $P$. syringae pv. tomato DC3000 carrying AvrRpt 2 turns out to be spatially separated, with the SA activation observed only 
in the cell layers surrounding the infection site and JA activation in the cell layers outside the SA zone (Betsuyaku et al. 2018). NPR1 has recently been shown to form SA-induced NPR1 condensate (SINC) in naïve leaf tissues adjacent to the infiltrated area directly responding to pathogen-delivered Avr proteins and undergoing HR. Formation of SINC promotes cell survival through sequestering stress-responsive proteins and recruits ubiquitination machinery to regulate protein homeostasis (Zavaliev et al. 2020). Both studies provided strong evidence for spatial coordination across the leaf tissues of responses initiated by NLRs. What molecules are used for communicating the signals between tissues in directly responding zones and surrounding regions and how the signals are recognized remains to be elucidated. Dissecting the signaling events in different zones would enable better understanding of coordination between NLR- and PRR-mediated signaling.

This further raises questions regarding which observed responses are cell autonomous and are responding directly to the recognized pathogen invasion signals, and which are cell nonautonomous and are responding instead to signals produced by the directly responding cells. Under physiological pathogen infection conditions or with a low-dose pathogen inoculation, the vast majority of cells would not directly encounter effectors. Consequently, only a very small percentage of the cells initiate NLR signaling, which are undergoing an HR. The initial steps in both PRR- and NLR-mediated signaling likely occur in a cell autonomous fashion (Fig. 2A). It has been demonstrated using a protoplast-based assay that RPS2-mediated HR cell death can occur autonomously in each cell (Wu et al. 2003). It is possible that PRR-mediated signaling occurs largely cell autonomously, whereas a significant portion of NLR-mediated responses other than HR cell death occur through nonautonomous means. It is plausible that, under natural conditions, only a small number of plant cells are engaged in NLR-mediated signaling and undergo $\mathrm{HR}$, releasing defense signals such as DAMPs, through both apoplastic and symplastic pathways. The neighboring cells detect such signals from the directly responding cells and initiate PRR-mediated signaling to reach the full spectrum of immune responses, while balancing the decisions of cell death and cell survival (Fig. 2B). The cell-nonautonomous model would explain the dependency of PRRs and coreceptors for defense responses activated by NLRs when examined at macroscopic scales, and is not mutually exclusive with the hypothesis that crosstalk between PRR- and NLR-mediated signaling occurs in the same cell. The lack of efficient highthroughput detection methods at single-cell resolution has hindered systemic exploration of this topic in plant tissues. It would be interesting to apply single-cell or single-nucleus RNA-sequencing technology together with imaging technique to analyze the spatiotemporal dynamics of various heterogeneously activated signaling pathways across the tissue.

\section{ACKNOWLEDGMENTS}

We thank F. Katagiri, N. Omae, T. Nobori, A. Mine, H. Guo, H. Adachi, and J. Glazebrook for critical reading of the manuscript.

\section{LITERATURE CITED}

Aarts, N., Metz, M., Holub, E., Staskawicz, B. J., Daniels, M. J., and Parker, J. E. 1998. Different requirements for EDS1 and NDR1 by disease resistance genes define at least two $\mathrm{R}$ gene-mediated signaling pathways in Arabidopsis. Proc. Natl. Acad. Sci. U.S.A. 95:10306-10311.

Adachi, H., Contreras, M. P., Harant, A., Wu, C. H., Derevnina, L., Sakai, T., Duggan, C., Moratto, E., Bozkurt, T. O., Maqbool, A., Win, J., and Kamoun, S. 2019a. An N-terminal motif in NLR immune receptors is functionally conserved across distantly related plant species. eLife 8: e49956.
Adachi, H., Derevnina, L., and Kamoun, S. 2019b. NLR singletons, pairs, and networks: Evolution, assembly, and regulation of the intracellular immunoreceptor circuitry of plants. Curr. Opin. Plant Biol. 50:121-131.

Adachi, H., Nakano, T., Miyagawa, N., Ishihama, N., Yoshioka, M., Katou, Y., Yaeno, T., Shirasu, K., and Yoshioka, H. 2015. WRKY transcription factors phosphorylated by MAPK regulate a plant immune NADPH oxidase in Nicotiana benthamiana. Plant Cell 27:2645-2663.

Albert, I., Böhm, H., Albert, M., Feiler, C. E., Imkampe, J., Wallmeroth, N., Brancato, C., Raaymakers, T. M., Oome, S., Zhang, H., Krol, E., Grefen, C., Gust, A. A., Chai, J., Hedrich, R., Van den Ackerveken, G., and Nürnberger, T. 2015. An RLP23-SOBIR1-BAK1 complex mediates NLP-triggered immunity. Nat. Plants 1:15140.

Andersson, E. R., Sandberg, R., and Lendahl, U. 2011. Notch signaling: Simplicity in design, versatility in function. Development 138: 3593-3612.

Asai, S., Furzer, O. J., Cevik, V., Kim, D. S., Ishaque, N., Goritschnig, S., Staskawicz, B. J., Shirasu, K., and Jones, J. D. G. 2018. A downy mildew effector evades recognition by polymorphism of expression and subcellular localization. Nat. Commun. 9:5192.

Betsuyaku, S., Katou, S., Takebayashi, Y., Sakakibara, H., Nomura, N., and Fukuda, H. 2018. Salicylic acid and jasmonic acid pathways are activated in spatially different domains around the infection site during effector-triggered immunity in Arabidopsis thaliana. Plant Cell Physiol. 59:8-16.

Bi, G., Zhou, Z., Wang, W., Li, L., Rao, S., Wu, Y., Zhang, X., Menke, F. L. H., Chen, S., and Zhou, J.-M. 2018. Receptor-like cytoplasmic kinases directly link diverse pattern recognition receptors to the activation of mitogen-activated protein kinase cascades in Arabidopsis. Plant Cell 30:1543-1561.

Bigeard, J., Colcombet, J., and Hirt, H. 2015. Signaling mechanisms in pattern-triggered immunity (PTI). Mol. Plant 8:521-539.

Bogdanove, A. J., Schornack, S., and Lahaye, T. 2010. TAL effectors: Finding plant genes for disease and defense. Curr. Opin. Plant Biol. 13: 394-401.

Boller, T., and He, S. Y. 2009. Innate immunity in plants: An arms race between pattern recognition receptors in plants and effectors in microbial pathogens. Science 324:742-744.

Boudsocq, M., Willmann, M. R., McCormack, M., Lee, H., Shan, L., He, P., Bush, J., Cheng, S.-H., and Sheen, J. 2010. Differential innate immune signalling via $\mathrm{Ca}^{2+}$ sensor protein kinases. Nature 464:418-422.

Cao, Y., Liang, Y., Tanaka, K., Nguyen, C. T., Jedrzejczak, R. P., Joachimiak, A., and Stacey, G. 2014. The kinase LYK5 is a major chitin receptor in Arabidopsis and forms a chitin-induced complex with related kinase CERK1. eLife 3:e03766.

Chen, T., Nomura, K., Wang, X., Sohrabi, R., Xu, J., Yao, L., Paasch, B. C. Ma, L., Kremer, J., Cheng, Y., Zhang, L., Wang, N., Wang, E., Xin, X.-F., and $\mathrm{He}, \mathrm{S}$. Y. 2020. A plant genetic network for preventing dysbiosis in the phyllosphere. Nature 580:653-657.

Chinchilla, D., Zipfel, C., Robatzek, S., Kemmerling, B., Nürnberger, T., Jones, J. D. G., Felix, G., and Boller, T. 2007. A flagellin-induced complex of the receptor FLS2 and BAK1 initiates plant defence. Nature 448:497-500.

Clough, S. J., Fengler, K. A., Yu, I. C., Lippok, B., Smith, R. K., Jr., and Bent, A. F. 2000. The Arabidopsis dnd1 "defense, no death" gene encodes a mutated cyclic nucleotide-gated ion channel. Proc. Natl. Acad. Sci. U.S.A. 97:9323-9328

Couto, D., and Zipfel, C. 2016. Regulation of pattern recognition receptor signalling in plants. Nat. Rev. Immunol. 16:537-552.

Cui, H., Qiu, J., Zhou, Y., Bhandari, D. D., Zhao, C., Bautor, J., and Parker, J. E. 2018. Antagonism of transcription factor MYC2 by EDS1/PAD4 complexes bolsters salicylic acid defense in Arabidopsis effectortriggered immunity. Mol. Plant 11:1053-1066.

Cui, H., Tsuda, K., and Parker, J. E. 2015. Effector-triggered immunity: From pathogen perception to robust defense. Annu. Rev. Plant Biol. 66: 487-511.

Day, B., Dahlbeck, D., and Staskawicz, B. J. 2006. NDR1 interaction with RIN4 mediates the differential activation of multiple disease resistance pathways in Arabidopsis. Plant Cell 18:2782-2791.

Dodds, P. N., and Rathjen, J. P. 2010. Plant immunity: Towards an integrated view of plant-pathogen interactions. Nat. Rev. Genet. 11: 539-548.

Domínguez-Ferreras, A., Kiss-Papp, M., Jehle, A. K., Felix, G., and Chinchilla, D. 2015. An overdose of the Arabidopsis coreceptor BRASSINOSTEROID INSENSITIVE1-ASSOCIATED RECEPTOR KINASE1 or its ectodomain causes autoimmunity in a SUPPRESSOR OF BIR1-1-dependent manner. Plant Physiol. 168:1106-1121.

Du, J., Gao, Y., Zhan, Y., Zhang, S., Wu, Y., Xiao, Y., Zou, B., He, K., Gou, X., Li, G., Lin, H., and Li, J. 2016. Nucleocytoplasmic trafficking is 
essential for BAK1- and BKK1-mediated cell-death control. Plant J. 85: 520-531.

Dubiella, U., Seybold, H., Durian, G., Komander, E., Lassig, R., Witte, C.-P., Schulze, W. X., and Romeis, T. 2013. Calcium-dependent protein kinase/NADPH oxidase activation circuit is required for rapid defense signal propagation. Proc. Natl. Acad. Sci. U.S.A. 110:8744-8749.

Durán, P., Thiergart, T., Garrido-Oter, R., Agler, M., Kemen, E., SchulzeLefert, P., and Hacquard, S. 2018. Microbial interkingdom interactions in roots promote Arabidopsis survival. Cell 175:973-983.e14.

Duxbury, Z., Wang, S., MacKenzie, C. I., Tenthorey, J. L., Zhang, X., Huh, S. U., Hu, L., Hill, L., Ngou, P. M., Ding, P., Chen, J., Ma, Y., Guo, H., Castel, B., Moschou, P. N., Bernoux, M., Dodds, P. N., Vance, R. E., and Jones, J. D. G. 2020. Induced proximity of a TIR signaling domain on a plant-mammalian NLR chimera activates defense in plants. Proc. Natl. Acad. Sci. U.S.A. 117:18832-18839.

Felix, G., Duran, J. D., Volko, S., and Boller, T. 1999. Plants have a sensitive perception system for the most conserved domain of bacterial flagellin. Plant J. 18:265-276.

Ferrari, S., Savatin, D. V., Sicilia, F., Gramegna, G., Cervone, F., and Lorenzo, G. D. 2013. Oligogalacturonides: Plant damage-associated molecular patterns and regulators of growth and development. Front. Plant Sci. 4:49.

Fitzpatrick, C. R., Salas-González, I., Conway, J. M., Finkel, O. M., Gilbert, S., Russ, D., Teixeira, P. J. P. L., and Dangl, J. L. 2020. The plant microbiome: From ecology to reductionism and beyond. Annu. Rev. Microbiol. 74:81-100.

Gao, X., Chen, X., Lin, W., Chen, S., Lu, D., Niu, Y., Li, L., Cheng, C., McCormack, M., Sheen, J., Shan, L., and He, P. 2013. Bifurcation of Arabidopsis NLR immune signaling via $\mathrm{Ca}^{2+}$-dependent protein kinases. PLoS Pathog. 9:e1003127.

Gilroy, S., Białasek, M., Suzuki, N., Górecka, M., Devireddy, A. R., Karpiński, S., and Mittler, R. 2016. ROS, calcium, and electric signals: Key mediators of rapid systemic signaling in plants. Plant Physiol. 171: 1606-1615.

Gong, B.-Q., Guo, J., Zhang, N., Yao, X., Wang, H.-B., and Li, J.-F. 2019. Cross-microbial protection via priming a conserved immune co-receptor through juxtamembrane phosphorylation in plants. Cell Host Microbe 26:810-822.e7.

Grant, M., Brown, I., Adams, S., Knight, M., Ainslie, A., and Mansfield, J. 2000. The RPM1 plant disease resistance gene facilitates a rapid and sustained increase in cytosolic calcium that is necessary for the oxidative burst and hypersensitive cell death. Plant J. 23:441-450.

Gronnier, J., Franck, C. M., Stegmann, M., DeFalco, T. A., Cifuentes, A. A., Dünser, K., Lin, W., Yang, Z., Kleine-Vehn, J., Ringli, C., and Zipfel, C. 2020. FERONIA regulates FLS2 plasma membrane nanoscale dynamics to modulate plant immune signaling. bioRxiv doi:10.1101/ 2020.07.20.212233

Gu, Y., Zebell, S. G., Liang, Z., Wang, S., Kang, B.-H., and Dong, X. 2016. Nuclear pore permeabilization is a convergent signaling event in effector-triggered immunity. Cell 166:1526-1538.e11.

Guse, A. H. 2004. Regulation of calcium signaling by the second messenger cyclic adenosine diphosphoribose (cADPR). Curr. Mol. Med. 4:239-248.

Gust, A. A., and Felix, G. 2014. Receptor like proteins associate with SOBIR1-type of adaptors to form bimolecular receptor kinases. Curr. Opin. Plant Biol. 21:104-111.

Halter, T., Imkampe, J., Mazzotta, S., Wierzba, M., Postel, S., Bücherl, C., Kiefer, C., Stahl, M., Chinchilla, D., Wang, X., Nürnberger, T., Zipfel, C., Clouse, S., Borst, J. W., Boeren, S., de Vries, S. C., Tax, F., and Kemmerling, B. 2014. The leucine-rich repeat receptor kinase BIR2 is a negative regulator of BAK1 in plant immunity. Curr. Biol. 24: 134-143.

Harris, J. M., Balint-Kurti, P., Bede, J. C., Day, B., Gold, S., Goss, E. M., Grenville-Briggs, L. J., Jones, K. M., Wang, A., Wang, Y., Mitra, R. M., Sohn, K. H., and Alvarez, M. E. 2020. What are the Top 10 Unanswered Questions in Molecular Plant-Microbe Interactions? Mol. Plant. Microbe Interact. 33:1354-1365.

Hartmann, M., and Zeier, J. 2019. N-hydroxypipecolic acid and salicylic acid: A metabolic duo for systemic acquired resistance. Curr. Opin. Plant Biol. 50:44-57.

Hatsugai, N., Igarashi, D., Mase, K., Lu, Y., Tsuda, Y., Chakravarthy, S., Wei, H. L., Foley, J. W., Collmer, A., Glazebrook, J., and Katagiri, F. 2017. A plant effector-triggered immunity signaling sector is inhibited by pattern-triggered immunity. EMBO J. 36:2758-2769.

Hayafune, M., Berisio, R., Marchetti, R., Silipo, A., Kayama, M., Desaki, Y., Arima, S., Squeglia, F., Ruggiero, A., Tokuyasu, K., Molinaro, A., Kaku, H., and Shibuya, N. 2014. Chitin-induced activation of immune signaling by the rice receptor $\mathrm{CEBiP}$ relies on a unique sandwich-type dimerization. Proc. Natl. Acad. Sci. U.S.A. 111:E404-E413.
He, K., Gou, X., Yuan, T., Lin, H., Asami, T., Yoshida, S., Russell, S. D., and Li, J. 2007. BAK1 and BKK1 regulate brassinosteroid-dependent growth and brassinosteroid-independent cell-death pathways. Curr. Biol. 17:1109-1115.

Horsefield, S., Burdett, H., Zhang, X., Manik, M. K., Shi, Y., Chen, J., Qi, T., Gilley, J., Lai, J.-S., Rank, M. X., Casey, L. W., Gu, W., Ericsson, D. J., Foley, G., Hughes, R. O., Bosanac, T., von Itzstein, M., Rathjen, J. P., Nanson, J. D., Boden, M., Dry, I. B., Williams, S. J., Staskawicz, B. J., Coleman, M. P., Ve, T., Dodds, P. N., and Kobe, B. 2019. NAD ${ }^{+}$ cleavage activity by animal and plant TIR domains in cell death pathways. Science 365:793-799.

Hu, M., Qi, J., Bi, G., and Zhou, J.-M. 2020. Bacterial effectors induce oligomerization of immune receptor ZAR1 in vivo. Mol. Plant 13: 793-801.

Huang, Y., Yin, C., Liu, J., Feng, B., Ge, D., Kong, L., Ortiz-Morea, F. A., Richter, J., Hauser, M.-T., Wang, W.-M., Shan, L., and He, P. 2020. A trimeric CrRLK1L-LLG1 complex genetically modulates SUMM2mediated autoimmunity. Nat. Commun. 11:4859.

Huffaker, A., Pearce, G., and Ryan, C. A. 2006. An endogenous peptide signal in Arabidopsis activates components of the innate immune response. Proc. Natl. Acad. Sci. U.S.A. 103:10098-10103.

Ishiga, Y., and Ichinose, Y. 2016. Pseudomonas syringae pv. tomato OxyR is required for virulence in tomato and Arabidopsis. Mol. Plant-Microbe Interact. 29:119-131.

Jones, J. D. G., and Dangl, J. L. 2006. The plant immune system. Nature 444:323-329.

Jurkowski, G. I., Smith, R. K., Jr., Yu, I. C., Ham, J. H., Sharma, S. B., Klessig, D. F., Fengler, K. A., and Bent, A. F. 2004. Arabidopsis DND2, a second cyclic nucleotide-gated ion channel gene for which mutation causes the "defense, no death" phenotype. Mol. Plant-Microbe Interact. 17:511-520.

Kadota, Y., Liebrand, T. W. H., Goto, Y., Sklenar, J., Derbyshire, P., Menke, F. L. H., Torres, M. A., Molina, A., Zipfel, C., Coaker, G., and Shirasu, K. 2019. Quantitative phosphoproteomic analysis reveals common regulatory mechanisms between effector- and PAMP-triggered immunity in plants. New Phytol. 221:2160-2175.

Kadota, Y., Sklenar, J., Derbyshire, P., Stransfeld, L., Asai, S., Ntoukakis, V., Jones, J. D., Shirasu, K., Menke, F., Jones, A., and Zipfel, C. 2014. Direct regulation of the NADPH oxidase RBOHD by the PRRassociated kinase BIK1 during plant immunity. Mol. Cell 54:43-55.

Kanyuka, K., and Rudd, J. J. 2019. Cell surface immune receptors: The guardians of the plant's extracellular spaces. Curr. Opin. Plant Biol. 50: $1-8$.

Kimura, S., Hunter, K., Vaahtera, L., Tran, H. C., Citterico, M., Vaattovaara, A., Rokka, A., Stolze, S. C., Harzen, A., Meißner, L., Wilkens, M. M. T., Hamann, T., Toyota, M., Nakagami, H., and Wrzaczek, M. 2020. CRK2 and $\mathrm{C}$-terminal phosphorylation of NADPH oxidase RBOHD regulate reactive oxygen species production in Arabidopsis. Plant Cell 32: 1063-1080.

Knepper, C., Savory, E. A., and Day, B. 2011. Arabidopsis NDR1 is an integrin-like protein with a role in fluid loss and plasma membrane-cell wall adhesion. Plant Physiol. 156:286-300.

Kong, Q., Qu, N., Gao, M., Zhang, Z., Ding, X., Yang, F., Li, Y., Dong, O. X., Chen, S., Li, X., and Zhang, Y. 2012. The MEKK1MKK1/MKK2-MPK4 kinase cascade negatively regulates immunity mediated by a mitogen-activated protein kinase kinase kinase in Arabidopsis. Plant Cell 24:2225-2236.

Kunze, G., Zipfel, C., Robatzek, S., Niehaus, K., Boller, T., and Felix, G. 2004. The $\mathrm{N}$ terminus of bacterial elongation factor $\mathrm{Tu}$ elicits innate immunity in Arabidopsis plants. Plant Cell 16:3496-3507.

Lapin, D., Bhandari, D. D., and Parker, J. E. 2020. Origins and immunity networking functions of EDS1 family proteins. Annu. Rev. Phytopathol. 58:253-276.

Lapin, D., Kovacova, V., Sun, X., Dongus, J. A., Bhandari, D., von Born, P., Bautor, J., Guarneri, N., Rzemieniewski, J., Stuttmann, J., Beyer, A., and Parker, J. E. 2019. A coevolved EDS1-SAG101-NRG1 module mediates cell death signaling by TIR-domain immune receptors. Plant Cell 31 : 2430-2455.

Lee, D., Lal, N. K., Lin, Z. D., Ma, S., Liu, J., Castro, B., Toruño, T., Dinesh-Kumar, S. P., and Coaker, G. 2020. Regulation of reactive oxygen species during plant immunity through phosphorylation and ubiquitination of RBOHD. Nat. Commun. 11:1838.

Li, L., Li, M., Yu, L., Zhou, Z., Liang, X., Liu, Z., Cai, G., Gao, L., Zhang, X., Wang, Y., Chen, S., and Zhou, J.-M. 2014. The FLS2-associated kinase BIK1 directly phosphorylates the NADPH oxidase RbohD to control plant immunity. Cell Host Microbe 15:329-338.

Liebrand, T. W. H., van den Berg, G. C. M., Zhang, Z., Smit, P., Cordewener, J. H. G., America, A. H. P., Sklenar, J., Jones, A. M. E., 
Tameling, W. I. L., Robatzek, S., Thomma, B. P. H. J., and Joosten, M. H. A. J. 2013. Receptor-like kinase SOBIR1/EVR interacts with receptor-like proteins in plant immunity against fungal infection. Proc. Natl. Acad. Sci. U.S.A. 110:10010-10015.

Ling, T., Bellin, D., Vandelle, E., Imanifard, Z., and Delledonne, M. 2017. Host-mediated $S$-nitrosylation disarms the bacterial effector HopAI1 to reestablish immunity. Plant Cell 29:2871-2881.

Liu, J., Huang, Y., Kong, L., Yu, X., Feng, B., Liu, D., Zhao, B., Mendes, G. C., Yuan, P., Ge, D., Wang, W.-M., Fontes, E. P. B., Li, P., Shan, L., and $\mathrm{He}, \mathrm{P}$. 2020. The malectin-like receptor-like kinase LETUM1 modulates NLR protein SUMM2 activation via MEKK2 scaffolding. Nat. Plants 6:1106-1115.

Liu, T., Liu, Z., Song, C., Hu, Y., Han, Z., She, J., Fan, F., Wang, J., Jin, C., Chang, J., Zhou, J.-M., and Chai, J. 2012. Chitin-induced dimerization activates a plant immune receptor. Science 336:1160-1164.

Liu, Y., Ren, D., Pike, S., Pallardy, S., Gassmann, W., and Zhang, S. 2007. Chloroplast-generated reactive oxygen species are involved in hypersensitive response-like cell death mediated by a mitogen-activated protein kinase cascade. Plant J. 51:941-954.

Liu, Z., Wu, Y., Yang, F., Zhang, Y., Chen, S., Xie, Q., Tian, X., and Zhou, J.-M. 2013. BIK1 interacts with PEPRs to mediate ethylene-induced immunity. Proc. Natl. Acad. Sci. U.S.A. 110:6205-6210.

Luo, X., Wu, W., Liang, Y., Xu, N., Wang, Z., Zou, H., and Liu, J. 2020. Tyrosine phosphorylation of the lectin receptor-like kinase LORE regulates plant immunity. EMBO J. 39:e102856

Ma, K.-W., Niu, Y., Jia, Y., Ordon, J., Copeland, C., Emonet, A., Geldner, N., Guan, R., Stolze, S., Nakagami, H., Garrido-Oter, R., and SchulzeLefert, P. 2020. Coordination of microbe-host homeostasis via a crosstalk with plant innate immunity. Research Square doi: 10.21203/rs.3.rs-69445/v1

Ma, X., Claus, L. A. N., Leslie, M. E., Tao, K., Wu, Z., Liu, J., Yu, X., Li, B., Zhou, J., Savatin, D. V., Peng, J., Tyler, B. M., Heese, A., Russinova, E., He, P., and Shan, L. 2020. Ligand-induced monoubiquitination of BIK1 regulates plant immunity. Nature 581:199-203.

Ma, Z., Song, T., Zhu, L., Ye, W., Wang, Y., Shao, Y., Dong, S., Zhang, Z., Dou, D., Zheng, X., Tyler, B. M., and Wang, Y. 2015. A Phytophthora sojae glycoside hydrolase 12 protein is a major virulence factor during soybean infection and is recognized as a PAMP. Plant Cell 27: 2057-2072.

Majhi, B. B., Sreeramulu, S., and Sessa, G. 2019. BRASSINOSTEROIDSIGNALING KINASE5 associates with immune receptors and is required for immune responses. Plant Physiol. 180:1166-1184.

Martin, R., Qi, T., Zhang, H., Liu, F., King, M., Toth, C., Nogales, E., and Staskawicz, B. J. 2020. Structure of the activated Roq1 resistosome directly recognizing the pathogen effector XopQ. bioRxiv doi: 10.1101/2020.08.13.246413

Mine, A., Berens, M. L., Nobori, T., Anver, S., Fukumoto, K., Winkelmüller, T. M., Takeda, A., Becker, D., and Tsuda, K. 2017. Pathogen exploitation of an abscisic acid- and jasmonate-inducible MAPK phosphatase and its interception by Arabidopsis immunity. Proc. Natl. Acad. Sci. U.S.A. 114:7456-7461.

Mine, A., Seyfferth, C., Kracher, B., Berens, M. L., Becker, D., and Tsuda, K. 2018. The defense phytohormone signaling network enables rapid, high-amplitude transcriptional reprogramming during effector-triggered immunity. Plant Cell 30:1199-1219.

Mitra, A. K., Sawada, K., Tiwari, P., Mui, K., Gwin, K., and Lengyel, E. 2011. Ligand-independent activation of c-Met by fibronectin and $\alpha_{5} \beta_{1^{-}}$integrin regulates ovarian cancer invasion and metastasis. Oncogene 30 : 1566-1576.

Miya, A., Albert, P., Shinya, T., Desaki, Y., Ichimura, K., Shirasu, K., Narusaka, Y., Kawakami, N., Kaku, H., and Shibuya, N. 2007. CERK1, a LysM receptor kinase, is essential for chitin elicitor signaling in Arabidopsis. Proc. Natl. Acad. Sci. U.S.A. 104:19613-19618.

Monteiro, F., and Nishimura, M. T. 2018. Structural, functional, and genomic diversity of plant NLR proteins: An evolved resource for rational engineering of plant immunity. Annu. Rev. Phytopathol. 56: 243-267.

Ngou, B. P. M., Ahn, H.-K., Ding, P., and Jones, J. D. G. 2020a. Mutual potentiation of plant immunity by cell-surface and intracellular receptors. bioRxiv doi:10.1101/2020.04.10.034173

Ngou, B. P. M., Ahn, H.-K., Ding, P., Redkar, A., Brown, H., Ma, Y., Youles, M., Tomlinson, L., and Jones, J. D. G. 2020b. Estradiol-inducible AvrRps4 expression reveals distinct properties of TIR-NLR-mediated effector-triggered immunity. J. Exp. Bot. 71:2186-2197.

Nobori, T., Velásquez, A. C., Wu, J., Kvitko, B. H., Kremer, J. M., Wang, Y., He, S. Y., and Tsuda, K. 2018. Transcriptome landscape of a bacterial pathogen under plant immunity. Proc. Natl. Acad. Sci. U.S.A. 115: E3055-E3064.
Nomura, K., Mecey, C., Lee, Y.-N., Imboden, L. A., Chang, J. H., and He, S. Y. 2011. Effector-triggered immunity blocks pathogen degradation of an immunity-associated vesicle traffic regulator in Arabidopsis. Proc. Natl. Acad. Sci. U.S.A. 108:10774-10779.

Petutschnig, E. K., Jones, A. M. E., Serazetdinova, L., Lipka, U., and Lipka, V. 2010. The lysin motif receptor-like kinase (LysM-RLK) CERK1 is a major chitin-binding protein in Arabidopsis thaliana and subject to chitin-induced phosphorylation. J. Biol. Chem. 285:28902-28911.

Postma, J., Liebrand, T. W. H., Bi, G., Evrard, A., Bye, R. R., Mbengue, M., Kuhn, H., Joosten, M. H. A. J., and Robatzek, S. 2016. Avr4 promotes Cf-4 receptor-like protein association with the BAK1/SERK3 receptorlike kinase to initiate receptor endocytosis and plant immunity. New Phytol. 210:627-642.

Qi, J., Wang, J., Gong, Z., and Zhou, J.-M. 2017. Apoplastic ROS signaling in plant immunity. Curr. Opin. Plant Biol. 38:92-100.

Qi, Y., Tsuda, K., Glazebrook, J., and Katagiri, F. 2011. Physical association of pattern-triggered immunity (PTI) and effector-triggered immunity (ETI) immune receptors in Arabidopsis. Mol. Plant Pathol. 12: 702-708.

Roux, M., Schwessinger, B., Albrecht, C., Chinchilla, D., Jones, A., Holton, N., Malinovsky, F. G., Tör, M., de Vries, S., and Zipfel, C. 2011. The Arabidopsis leucine-rich repeat receptor-like kinases BAK1/SERK3 and BKK1/SERK4 are required for innate immunity to hemibiotrophic and biotrophic pathogens. Plant Cell 23:2440-2455.

Russinova, E., Borst, J.-W., Kwaaitaal, M., Caño-Delgado, A., Yin, Y., Chory, J., and de Vries, S. C. 2004. Heterodimerization and endocytosis of Arabidopsis brassinosteroid receptors BRI1 and AtSERK3 (BAK1). Plant Cell 16:3216-3229.

Saijo, Y., Loo, E. P., and Yasuda, S. 2018. Pattern recognition receptors and signaling in plant-microbe interactions. Plant J. 93:592-613.

Saile, S. C., Jacob, P., Castel, B., Jubic, L. M., Salas-Gonzáles, I., Bäcker, M., Jones, J. D. G., Dangl, J. L., and El Kasmi, F. 2020. Two unequally redundant "helper" immune receptor families mediate Arabidopsis thaliana intracellular "sensor" immune receptor functions. PLoS Biol. 18:e3000783.

Schultink, A., Qi, T., Lee, A., Steinbrenner, A. D., and Staskawicz, B. 2017. Roq1 mediates recognition of the Xanthomonas and Pseudomonas effector proteins XopQ and HopQ1. Plant J. 92:787-795.

Schulze, B., Mentzel, T., Jehle, A. K., Mueller, K., Beeler, S., Boller, T., Felix, G., and Chinchilla, D. 2010. Rapid heteromerization and phosphorylation of ligand-activated plant transmembrane receptors and their associated kinase BAK1. J. Biol. Chem. 285:9444-9451.

Schwessinger, B., Roux, M., Kadota, Y., Ntoukakis, V., Sklenar, J., Jones, A., and Zipfel, C. 2011. Phosphorylation-dependent differential regulation of plant growth, cell death, and innate immunity by the regulatory receptor-like kinase BAK1. PLoS Genet. 7:e1002046.

Shen, Q., Bourdais, G., Pan, H., Robatzek, S., and Tang, D. 2017. Arabidopsis glycosylphosphatidylinositol-anchored protein LLG1 associates with and modulates FLS2 to regulate innate immunity. Proc. Natl. Acad. Sci. U.S.A. 114:5749-5754.

Shi, H., Shen, Q., Qi, Y., Yan, H., Nie, H., Chen, Y., Zhao, T., Katagiri, F., and Tang, D. 2013. BR-SIGNALING KINASE1 physically associates with FLAGELLIN SENSING2 and regulates plant innate immunity in Arabidopsis. Plant Cell 25:1143-1157.

Shibuya, N., and Minami, E. 2001. Oligosaccharide signalling for defence responses in plant. Physiol. Mol. Plant Pathol. 59:223-233.

Shimizu, T., Nakano, T., Takamizawa, D., Desaki, Y., Ishii-Minami, N., Nishizawa, Y., Minami, E., Okada, K., Yamane, H., Kaku, H., and Shibuya, N. 2010. Two LysM receptor molecules, CEBiP and OsCERK1, cooperatively regulate chitin elicitor signaling in rice. Plant J. 64: 204-214.

Shinya, T., Yamaguchi, K., Desaki, Y., Yamada, K., Narisawa, T., Kobayashi, Y., Maeda, K., Suzuki, M., Tanimoto, T., Takeda, J., Nakashima, M., Funama, R., Narusaka, M., Narusaka, Y., Kaku, H., Kawasaki, T., and Shibuya, N. 2014. Selective regulation of the chitininduced defense response by the Arabidopsis receptor-like cytoplasmic kinase PBL27. Plant J. 79:56-66

Smakowska-Luzan, E., Mott, G. A., Parys, K., Stegmann, M., Howton, T. C., Layeghifard, M., Neuhold, J., Lehner, A., Kong, J., Grünwald, K., Weinberger, N., Satbhai, S. B., Mayer, D., Busch, W., Madalinski, M., Stolt-Bergner, P., Provart, N. J., Mukhtar, M. S., Zipfel, C., Desveaux, D., Guttman, D. S., and Belkhadir, Y. 2018. An extracellular network of Arabidopsis leucine-rich repeat receptor kinases. Nature 553:342-346

Stegmann, M., Monaghan, J., Smakowska-Luzan, E., Rovenich, H., Lehner, A., Holton, N., Belkhadir, Y., and Zipfel, C. 2017. The receptor kinase FER is a RALF-regulated scaffold controlling plant immune signaling. Science 355:287-289. 
Steinbuck, M. P., Arakcheeva, K., and Winandy, S. 2018. Novel TCRmediated mechanisms of Notch activation and signaling. J. Immunol. 200:997-1007.

Stringlis, I. A., Proietti, S., Hickman, R., Van Verk, M. C., Zamioudis, C., and Pieterse, C. M. J. 2018. Root transcriptional dynamics induced by beneficial rhizobacteria and microbial immune elicitors reveal signatures of adaptation to mutualists. Plant J. 93:166-180.

Su, J., Yang, L., Zhu, Q., Wu, H., He, Y., Liu, Y., Xu, J., Jiang, D., and Zhang, S. 2018. Active photosynthetic inhibition mediated by MPK3/MPK6 is critical to effector-triggered immunity. PLoS Biol. 16: e2004122.

Sun, Y., Li, L., Macho, A. P., Han, Z., Hu, Z., Zipfel, C., Zhou, J.-M., and Chai, J. 2013. Structural basis for flg22-induced activation of the Arabidopsis FLS2-BAK1 immune complex. Science 342:624-628.

Tanaka, K., Choi, J., Cao, Y., and Stacey, G. 2014. Extracellular ATP acts as a damage-associated molecular pattern (DAMP) signal in plants. Front. Plant Sci. 5:446.

Tateda, C., Zhang, Z., Shrestha, J., Jelenska, J., Chinchilla, D., and Greenberg, J. T. 2014. Salicylic acid regulates Arabidopsis microbial pattern receptor kinase levels and signaling. Plant Cell 26:4171-4187.

Tian, W., Hou, C., Ren, Z., Wang, C., Zhao, F., Dahlbeck, D., Hu, S., Zhang, L., Niu, Q., Li, L., Staskawicz, B. J., and Luan, S. 2019. A calmodulingated calcium channel links pathogen patterns to plant immunity. Nature 572:131-135.

Tian, W., Wang, C., Gao, Q., Li, L., and Luan, S. 2020. Calcium spikes, waves and oscillations in plant development and biotic interactions. Nat. Plants 6:750-759.

Torres, M. A. 2010. ROS in biotic interactions. Physiol. Plant. 138:414-429.

Tsuda, K., and Katagiri, F. 2010. Comparing signaling mechanisms engaged in pattern-triggered and effector-triggered immunity. Curr. Opin. Plant Biol. 13:459-465.

Tsuda, K., Mine, A., Bethke, G., Igarashi, D., Botanga, C. J., Tsuda, Y., Glazebrook, J., Sato, M., and Katagiri, F. 2013. Dual regulation of gene expression mediated by extended MAPK activation and salicylic acid contributes to robust innate immunity in Arabidopsis thaliana. PLoS Genet. 9:e1004015.

Tsuda, K., Sato, M., Stoddard, T., Glazebrook, J., and Katagiri, F. 2009. Network properties of robust immunity in plants. PLoS Genet. 5: e1000772.

van der Burgh, A. M., and Joosten, M. H. A. J. 2019. Plant immunity: Thinking outside and inside the box. Trends Plant Sci. 24:587-601.

van der Burgh, A. M., Postma, J., Robatzek, S., and Joosten, M. H. A. J. 2019. Kinase activity of SOBIR1 and BAK1 is required for immune signalling. Mol. Plant Pathol. 20:410-422.

Wan, J., Zhang, X.-C., Neece, D., Ramonell, K. M., Clough, S., Kim, S. Y., Stacey, M. G., and Stacey, G. 2008. A LysM receptor-like kinase plays a critical role in chitin signaling and fungal resistance in Arabidopsis. Plant Cell 20:471-481.

Wan, L., Essuman, K., Anderson, R. G., Sasaki, Y., Monteiro, F., Chung, E.-H., Osborne Nishimura, E., DiAntonio, A., Milbrandt, J., Dangl, J. L., and Nishimura, M. T. 2019. TIR domains of plant immune receptors are $\mathrm{NAD}^{+}$-cleaving enzymes that promote cell death. Science 365:799-803.

Wang, C., Wang, G., Zhang, C., Zhu, P., Dai, H., Yu, N., He, Z., Xu, L., and Wang, E. 2017. OsCERK1-Mediated Chitin Perception and Immune Signaling Requires Receptor-like Cytoplasmic Kinase 185 to Activate an MAPK Cascade in Rice. Mol. Plant 10:619-633.

Wang, J., Grubb, L. E., Wang, J., Liang, X., Li, L., Gao, C., Ma, M., Feng, F., Li, M., Li, L., Zhang, X., Yu, F., Xie, Q., Chen, S., Zipfel, C. Monaghan, J., and Zhou, J.-M. 2018. A regulatory module controlling homeostasis of a plant immune kinase. Mol. Cell 69:493-504.e6.

Wang, J., Hu, M., Wang, J., Qi, J., Han, Z., Wang, G., Qi, Y., Wang, H.-W., Zhou, J.-M., and Chai, J. 2019a. Reconstitution and structure of a plant NLR resistosome conferring immunity. Science 364:eaav5870.

Wang, J., Liu, X., Zhang, A., Ren, Y., Wu, F., Wang, G., Xu, Y., Lei, C., Zhu, S., Pan, T., Wang, Y., Zhang, H., Wang, F., Tan, Y.-Q., Wang, Y., Jin, X., Luo, S., Zhou, C., Zhang, X., Liu, J., Wang, S., Meng, L., Wang, Y., Chen, X., Lin, Q., Zhang, X., Guo, X., Cheng, Z., Wang, J., Tian, Y., Liu, S., Jiang, L., Wu, C., Wang, E., Zhou, J.-M., Wang, Y.-F., Wang, H., and Wan, J. 2019b. A cyclic nucleotide-gated channel mediates cytoplasmic calcium elevation and disease resistance in rice. Cell Res. 29:820-831

Wang, J., Wang, J., Hu, M., Wu, S., Qi, J., Wang, G., Han, Z., Qi, Y., Gao, N., Wang, H.-W., Zhou, J.-M., and Chai, J. 2019c. Ligand-triggered allosteric ADP release primes a plant NLR complex. Science 364 eaav5868.

Wang, Y., Schuck, S., Wu, J., Yang, P., Döring, A.-C., Zeier, J., and Tsuda, K. 2018a. A MPK3/6-WRKY33-ALD1-pipecolic acid regulatory loop contributes to systemic acquired resistance. Plant Cell 30:2480-2494.
Wang, Y., Xu, Y., Sun, Y., Wang, H., Qi, J., Wan, B., Ye, W., Lin, Y., Shao, Y., Dong, S., Tyler, B. M., and Wang, Y. 2018b. Leucine-rich repeat receptor-like gene screen reveals that Nicotiana RXEG1 regulates glycoside hydrolase 12 MAMP detection. Nat. Commun. 9:594.

Willmann, R., Lajunen, H. M., Erbs, G., Newman, M.-A., Kolb, D., Tsuda, K., Katagiri, F., Fliegmann, J., Bono, J.-J., Cullimore, J. V., Jehle, A. K., Götz, F., Kulik, A., Molinaro, A., Lipka, V., Gust, A. A., and Nürnberger, T. 2011. Arabidopsis lysin-motif proteins LYM1 LYM3 CERK1 mediate bacterial peptidoglycan sensing and immunity to bacterial infection. Proc. Natl. Acad. Sci. U.S.A. 108:19824-19829.

Wu, C.-H., Abd-El-Haliem, A., Bozkurt, T. O., Belhaj, K., Terauchi, R., Vossen, J. H., and Kamoun, S. 2017. NLR network mediates immunity to diverse plant pathogens. Proc. Natl. Acad. Sci. U.S.A. 114:8113-8118.

Wu, F., Chi, Y., Jiang, Z., Xu, Y., Xie, L., Huang, F., Wan, D., Ni, J., Yuan, F., Wu, X., Zhang, Y., Wang, L., Ye, R., Byeon, B., Wang, W., Zhang, S., Sima, M., Chen, S., Zhu, M., Pei, J., Johnson, D. M., Zhu, S., Cao, X., Pei, C., Zai, Z., Liu, Y., Liu, T., Swift, G. B., Zhang, W., Yu, M., Hu, Z., Siedow, J. N., Chen, X., and Pei, Z.-M. 2020. Hydrogen peroxide sensor HPCA1 is an LRR receptor kinase in Arabidopsis. Nature 578:577-581.

Wu, Y., Gao, Y., Zhan, Y., Kui, H., Liu, H., Yan, L., Kemmerling, B., Zhou, J.-M., He, K., and Li, J. 2020. Loss of the common immune coreceptor BAK1 leads to NLR-dependent cell death. Proc. Natl. Acad. Sci. U.S.A. 117:27044.

Wu, Y., Kuzma, J., Maréchal, E., Graeff, R., Lee, H. C., Foster, R., and Chua, N. H. 1997. Abscisic acid signaling through cyclic ADP-ribose in plants. Science 278:2126-2130.

Wu, Y., Wood, M. D., Tao, Y., and Katagiri, F. 2003. Direct delivery of bacterial avirulence proteins into resistant Arabidopsis protoplasts leads to hypersensitive cell death. Plant J. 33:131-137.

Wu, Z., Li, M., Dong, O. X., Xia, S., Liang, W., Bao, Y., Wasteneys, G., and Li, X. 2019. Differential regulation of TNL-mediated immune signaling by redundant helper CNLs. New Phytol. 222:938-953.

Xiao, Y., Stegmann, M., Han, Z., DeFalco, T. A., Parys, K., Xu, L., Belkhadir, Y., Zipfel, C., and Chai, J. 2019. Mechanisms of RALF peptide perception by a heterotypic receptor complex. Nature 572: 270-274.

Xu, H., and Heath, M. C. 1998. Role of calcium in signal transduction during the hypersensitive response caused by basidiospore-derived infection of the cowpea rust fungus. Plant Cell 10:585-597.

Yamaguchi, K., Yamada, K., Ishikawa, K., Yoshimura, S., Hayashi, N., Uchihashi, K., Ishihama, N., Kishi-Kaboshi, M., Takahashi, A., Tsuge, S., Ochiai, H., Tada, Y., Shimamoto, K., Yoshioka, H., and Kawasaki, T. 2013. A receptor-like cytoplasmic kinase targeted by a plant pathogen effector is directly phosphorylated by the chitin receptor and mediates rice immunity. Cell Host Microbe 13:347-357.

Yu, X., Xu, G., Li, B., de Souza Vespoli, L., Liu, H., Moeder, W., Chen, S., de Oliveira, M. V. V., Ariádina de Souza, S., Shao, W., Rodrigues, B., Ma, Y., Chhajed, S., Xue, S., Berkowitz, G. A., Yoshioka, K., He, P., and Shan, L. 2019. The receptor kinases BAK1/SERK4 regulate $\mathrm{Ca}^{2+}$ channel-mediated cellular homeostasis for cell death containment. Curr. Biol. 29:3778-3790.e8.

Yuan, M., Jiang, Z., Bi, G., Nomura, K., Liu, M., He, S. Y., Zhou, J.-M., and Xin, X.-F. 2020. Pattern-recognition receptors are required for NLRmediated plant immunity. bioRxiv doi:10.1101/2020.04.10.031294

Zavaliev, R., Mohan, R., Chen, T., and Dong, X. 2020. Formation of NPR1 condensates promotes cell survival during the plant immune response. Cell 182:1093-1108.e18.

Zhang, J., Li, W., Xiang, T., Liu, Z., Laluk, K., Ding, X., Zou, Y., Gao, M., Zhang, X., Chen, S., Mengiste, T., Zhang, Y., and Zhou, J.-M. 2010. Receptor-like cytoplasmic kinases integrate signaling from multiple plant immune receptors and are targeted by a Pseudomonas syringae effector. Cell Host Microbe 7:290-301.

Zhang, J., Yin, Z., and White, F. 2015. TAL effectors and the executor R genes. Front. Plant Sci. 6:641.

Zhang, M., Chiang, Y.-H., Toruño, T. Y., Lee, D., Ma, M., Liang, X., Lal, N. K., Lemos, M., Lu, Y.-J., Ma, S., Liu, J., Day, B., Dinesh-Kumar, S. P., Dehesh, K., Dou, D., Zhou, J.-M., and Coaker, G. 2018. The MAP4 kinase SIK1 ensures robust extracellular ROS burst and antibacterial immunity in plants. Cell Host Microbe 24:379-391.e5.

Zhang, Z., Liu, Y., Huang, H., Gao, M., Wu, D., Kong, Q., and Zhang, Y 2017. The NLR protein SUMM2 senses the disruption of an immune signaling MAP kinase cascade via CRCK3. EMBO Rep. 18:292-302.

Zhang, Z., Wu, Y., Gao, M., Zhang, J., Kong, Q., Liu, Y., Ba, H., Zhou, J., and Zhang, Y. 2012. Disruption of PAMP-induced MAP kinase cascade by a Pseudomonas syringae effector activates plant immunity mediated by the NB-LRR protein SUMM2. Cell Host Microbe 11:253-263.

Zhou, J.-M., and Zhang, Y. 2020. Plant immunity: Danger perception and signaling. Cell 181:978-989. 